
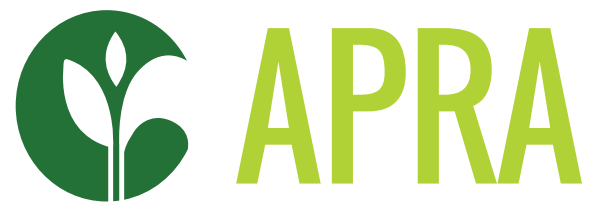

Agricultural Policy Research in Africa

\title{
THE RISE OF MEDIUM-SCALE FARMS IN THE NORTHERN SAVANNAH OF GHANA: FARMLAND INVASION OR AN INCLUSIVE COMMERCIALISED AGRICULTURAL REVOLUTION?
}

Joseph A. Yaro, Ibrahim Wahab, Gloria Afful-Mensah, and Michael Ben Awenam 


\section{CONTENTS}

Acknowledgements and disclaimer 4

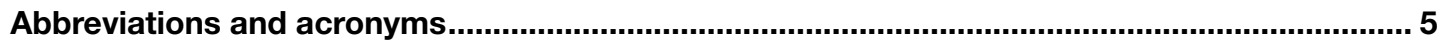

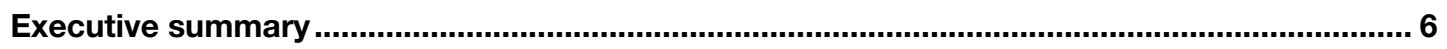

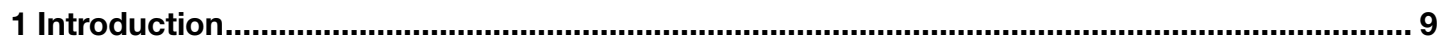

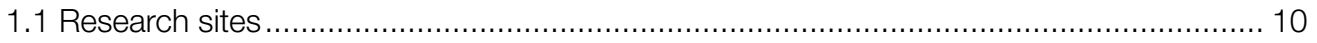

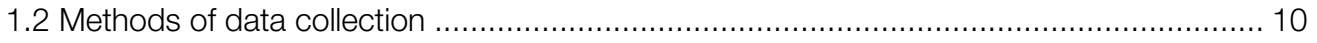

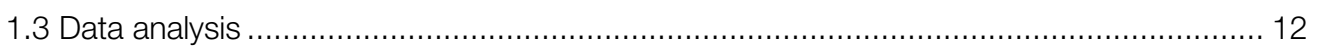

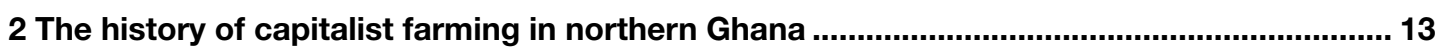

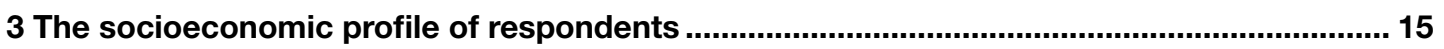

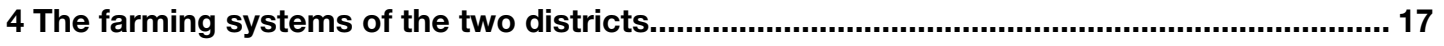

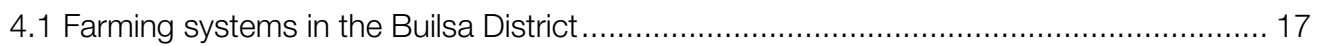

4.2 Farming systems in the Karaga District of the Northern Region..................................... 20

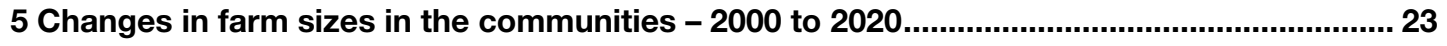

6 Factors of production: usage and dynamics by different categories of farmers ................... 27

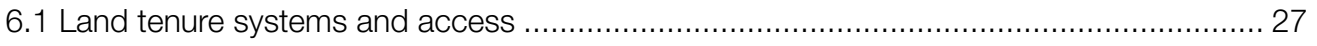

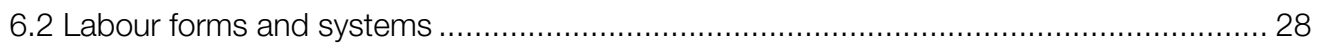

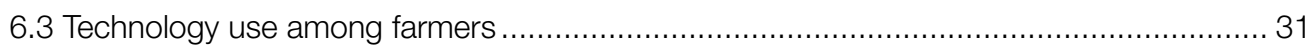

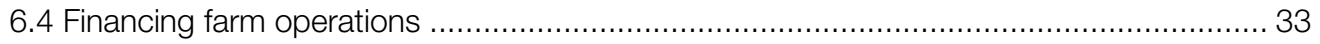

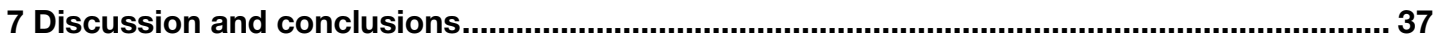

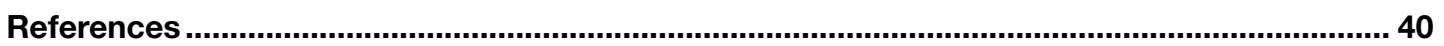

\section{List of tables}

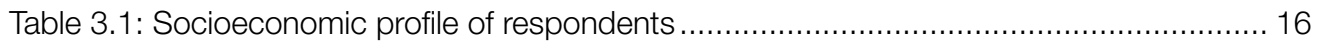

Table 5.1: Changing farm structure by locality (2000-2020) ............................................. 24

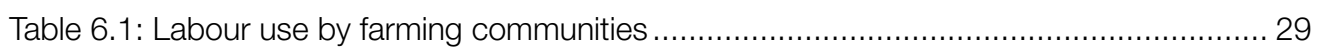

Table 6.2: Labour use by the scale of operation and farming system ................................ 30

Table 6.3: Technology use by farming communities ........................................................ 32

Table 6.4: Technology use by farming systems and farm scale........................................ 32

\section{List of figures}

Figure 1.1: Map of Karaga District showing research communities................................... 10

Figure 1.2: Map of Builsa District showing the research communities.................................. 11

Figure 4.1: Spatial configuration of compound farms of a selected household in Uwasi ........ 17

Figure 4.2: A sample of riverine farms along the banks of River Sissili in Weisi...................... 19 


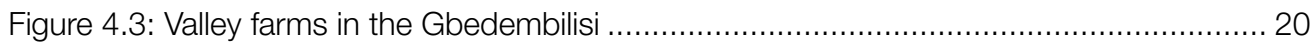

Figure 4.4: Upland farms in Nyong showing the different crops cultivated ............................ 21

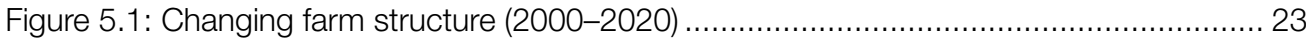

Figure 5.2: Changing farm structure among female farmers (2000-2020) .......................... 25

Figure 5.3: Changing farm structure among male farmers (2000-2020) .............................. 25

Figure 6.1: Sources of finance by the scale of production .............................................. 34

Figure 6.2: Sources of finance by farming systems ……................................................. 35 


\section{AGKNOWLEDGEMENTS AND DISCLAIMER}

We thank the chiefs and people of Karaga traditional area and the Builsa communities for their support in providing responses to our questions, showing us their fields and detailing the changes in the agricultural history of their communities and districts.

Joseph Awetori Yaro is Professor in the Department of Geography and Resource Development, University of Ghana. Ibrahim Wahab is a Postdoc in the Department of Human Geography, Lund University, Sweden. Gloria Afful-Mensah is an Economist with the Department of Economics, University of Ghana. Michael Ben Awenam is a Human Geographer with the Department of Geography and Resource Development, University of Ghana.

This working paper is funded with UK aid from the UK government (Foreign, Commonwealth \& Development Office - FCDO, formerly DFID). The opinions are the authors and do not necessarily reflect the views or policies of IDS or the UK government 


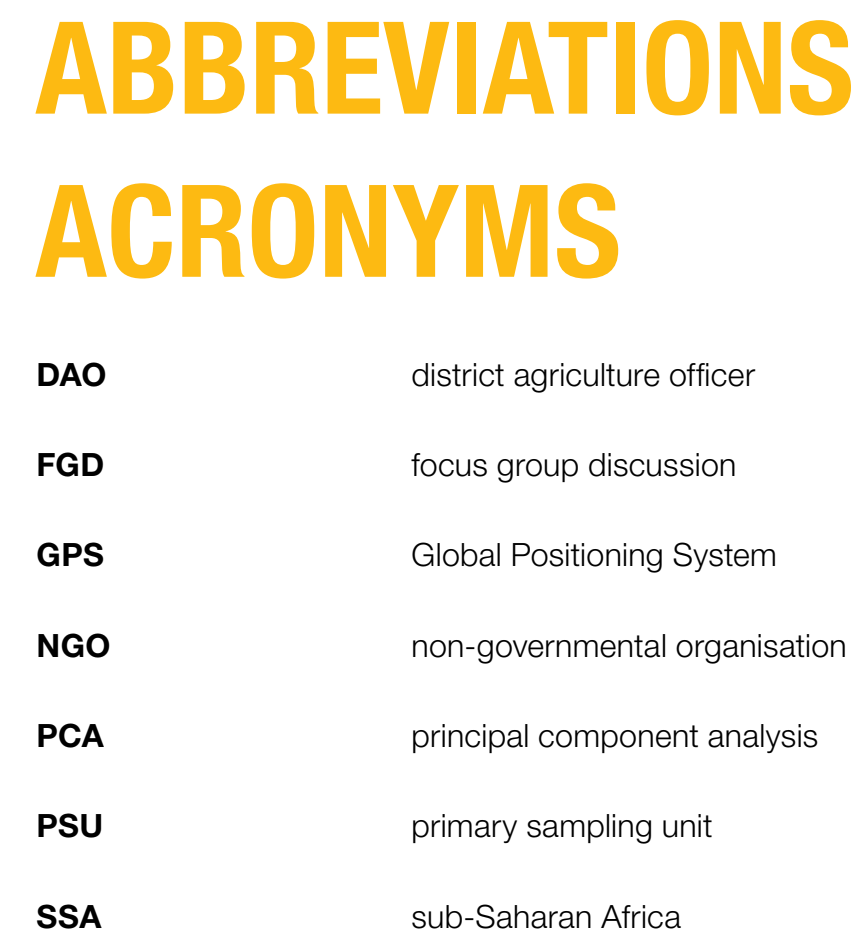




\section{EXECUTIVE SUMMARY}

Agriculture in sub-Saharan Africa (SSA) is undergoing rapid transformation involving major changes infarmland ownership and farm scales from small to medium farms, with the widespread use of mechanisation and agroinputs. Generally, households are increasing their farm sizes while others are dropping out of agriculture as the non-farm economy grows in both rural and urban areas. This study examined the changes in farmland sizes in two districts in the north of Ghana where agricultural extensification is still possible. The study used a mixedmethod approach triangulating qualitative, quantitative, farm mapping and historical information. Specifically, the study addressed the questions of the historical agrarian context; the magnitude and character of farm structure changes; the emerging spatial manifestation of farms; and the use of factors of production among the emerging socially differentiated farmers.

The north of Ghana is a late comer in the development of its agricultural potential, as the colonial administration intentionally neglected its socio-economic development to ensure a steady flow of labour southwards to cocoa farms and mines. Despite the huge agricultural potential of large plains and valleys, which are suitable for cereal and vegetable cultivation and amenable to modern mechanised production systems, the area saw no significant investments and development programmes. Immediately after independence in the late 1950s, a series of agriculture modernisation programmes were implemented in the area as a result of the nationalist agenda of providing Ghana's food from the north. The initial socialist approaches to national development created pockets of development, while the subsequent populist strategies simply led to the hijacking of state resources by people in business, the elite, the military, and urban-based farmers with little trickle-down effects to local rural farmers. The initial optimism shown by the high productivity and outputs from these medium and large farms, complemented by the several smallholder farmers who benefitted from state mechanisation and land clearance services, was short-lived as the resources ran dry and the failure to anticipate the need for agro-processing of the consequent massively increased production created a demand crisis. The economic crisis of the 1970s and the subsequent shift to a globalised neoliberal order led to further crumpling of the north's agricultural sector. Export crops favoured by the new state revived the southern economy, while northern staple food production suffered. The role of the state has been phenomenal in introducing modern technologies, such as tractors and combine harvesters, for modernising agriculture. These technologies contributed significantly to the growth of farmlands in the 1960s and 1970s when national food self-sufficiency goals reigned. The growth of farms has therefore always been associated with the differentiation of the peasantry, accorded by the ability of different groups to appropriate state resources. Certainly, generic benefits accrue to all categories of farmers as communication infrastructure is improved, mechanisation centres are established, new crop cultivars are introduced, and agro-inputs are subsidised. A landscape of winners and losers dominated the political economy of northern agrarian development initiatives in the 1960s and 1970s, which lay the bedrock for understanding contemporary processes of change in the area.

The present study was carried out in two districts Karaga District of the Northern Region and the Builsa South District of the Upper East Region - in Ghana. The average age of farmers in both districts is 43 years, with a significant majority (60 per cent) lacking any formal education. There is also an improved poverty status, with about 24 per cent being poor compared to poverty levels as high as 60 per cent two decades ago, which has led to improvements in the northern farmers' wellbeing. The number of farmers graduating into the lower-medium size farm category over the past two decades is phenomenal, with only a few migrant farmers constituting the large farm category. Generally, two trends are obvious; a rise in medium-scale farming (particularly lower-medium); and a decline in the small-scale farming category. The percentage of farmers operating on a lower-medium scale has more than doubled from 2000-2020. At the same time, the percentage of farmers operating on a small scale has declined by almost half (from 76.4 per cent in 2000 to 36.3 per cent in 2020). The rise among female farmers is relatively gradual compared to their male counterparts. Women are still predominantly smallscale farmers, with over 60 per cent of them in this 
category, while only 27 per cent of men remained in this category in 2020. All large-scale farmers are male, and this value has been stable over the last 15 years.

The growth in farmland size is typical within the uplands and valleys for both districts, but also very high for riverine farms in the Fumbisi area. The availability of land and its suitability for growing commercial crops demanded by urban markets explains the growth of farms in these farming systems. Compound farms are still important in the Fumbisi area, but are dwindling in importance in the Karaga District due to the destruction by livestock and the cost of fencing. There are changes in the crop mix on the farming systems typified by the gradual decline of traditional crops, such as sorghum, millet, beans, and other pulses. The new commercial crops emerging are cowpea, groundnuts, maize, rice and soybean, which are occupying the majority of farms. Spatially, groundnuts, maize and soybean are the major crops in the Karaga District, while the Fumbisi area is dominated by cowpea, maize and rice. The introduction of improved varieties of maize has made this crop an important household food security and cash crop.

The rise in medium-scale farming and the commercialisation of agriculture has implications for changes in the factors of agricultural production. Notable changes in land tenure, labour relations, and social systems are occurring as the systems adjust to the new dictates. Structurally, the traditional systems of accessing land remain but with qualitative changes involving struggles for control in managing land, rights to appropriate rents, and routes of access by women and migrants. Land is becoming scarcer and more valuable as a scramble for farmlands is underway by all social groups. Chiefs in the Fumbisi area are exercising their rights over land in contravention of tradition, which places land under the Earth Priest. Increasing rents to land are appropriated by chiefs in the Karaga area, thereby favouring migrants who pay rents and provide mechanisation services to chiefs. Within households, independent search for lands is on the increase outside of family lands. Women's access to land is easy for richer women but difficult for their poorer counterparts who still need to negotiate both traditional and modern monetised procedures. Access to land is still mainly traditionally granted, although untold and unformalised sums of cash and in-kind payments accompany these transactions. Social differentiation is correlated with the acreages of land farmers acquire, as those with easy access to fertile lands accumulate more and this spawns new forms of social relations in the community.

Changes in labour are spectacular as more labour is obtained from outside the household, especially for upper-medium-scale and large farmers. Also, due to the seasonal nature of farming, farm operations occur at the same time, thereby necessitating the use of hired labour by even the lower-medium farmers. Only small-scale farmers provide over 80 per cent of their labour needs from family labour. Many grown household members have some relative independence from the control over their labour by the head. This has been possible because of individuals' easier and increased access to non-family lands, and hence their independence from the allocator of family lands. Selling their labour to large- and medium-scale farmers to finance their own farms also explains the economic independence, though this is not to suggest that members of families do not provide labour to the household heads' farm. Labour exchanges between different farmer scales is an important part of the social differentiation process as larger-scale farmers can afford to pay for the services of smaller ones, thereby completing crucial farm-level operations to guarantee better outputs than the smaller ones.

Farming in the two districts has been modernising and commercialising rapidly over the past two decades, as more farmers are using mechanisation services and external agro-inputs as a result of government programmes and the support of non-governmental organisations (NGOs) in the context of improving markets and road infrastructure. Even smaller farmers recorded over 80 per cent usage of tractors and the use of mechanised processing of their farm outputs. This is especially true for groundnuts, maize and rice. This proves that modern machinery adoption is not dependent on farm size. However, since the state cannot run mechanisation centres efficiently, there is the need for a few larger-scale farmers in the uppermiddle and large farm category to own tractors to grant access to smaller farmers. The upper-medium farmers are the best diffusers of innovation because they do not have large holdings to make optimal use of their equipment, and are thus compelled to provide services to lower-medium and small-scale farmers to break even, thereby creating a win-win situation. Larger farmers may only be useful to chiefs who grant them access to land, as they provide the latter with ploughing services and act as conduits to fertiliser and other inputs. The usage of herbicides and weedicides is widespread among all categories of farmers, but with universal applicability for larger farmers. Due to government subsidies, fertiliser usage is as high among the small and lower-medium-scale farmers as it is by upper-medium and large farmers. The use of improved seeds is only common among upper-medium and large farmers, as smaller farmers shy away due to the cost of seeds and their reliability. Generally, the use of all four inputs for farming is positively correlated with the size of farms. 
The source of finance for farming is varied among the different farm sizes, as smaller farmers depend on livestock, wages from labouring on bigger farms, and sale of farm produce, while bigger farmers have access to loans, salaries from other jobs, and reinvestments from farming. The interdependence of the different farm scales on each other for investment capital through wages and deferred services, such as tractor ploughing and non-cash payments for harvesting and processing, is an important feature engendering the co-dependence and survival of the social relations.

The modernisation and commercialisation of agriculture in the two districts is phenomenal, making them important players in Ghana's food markets. The system of interdependence among the different farm scales regulates the processes of social differentiation and wealth accumulation, thereby preventing a widespread abuse of farmland rights amid a scramble for more land to expand production. The emerging social relations of production ensures a growing agricultural revolution, although more apparent with larger and more resourceful farmers than smaller ones. But collectively, the smaller farmers are a force to reckon with as they forge ahead with the help of the state and urban-based farmers. The study's findings underscore the critical point that agricultural modernisation and commercialisation are not constrained by farm scale. The divisibility in the use of mechanisation services has been impressive, and the importance of upper-medium farmers with access to modern farm machinery and the mutual benefits of sharing with small and lowermedium-scale farmers to reach optimality and recoup their investments is notable.

To create equitable, inclusive commercialised agrarian change, there is a need to address the problems of land inequity and access rules, innovation diffusion, cost of inputs and functioning value chains or agricultural markets. It is critical to examine the difficult problem of adoption of improved seeds among the small and lower medium-scale farmers by addressing the technical and social structure of the production and propagation of these seeds. The importance of the state, development partners and private sector actors in today's commercial agriculture is nonnegotiable. These actors need to invest in innovation to produce appropriate home-grown mechanisation and agro-processing equipment with the accompanying development of human capacities. Also, the current rigidity in marketing needs to be addressed using both traditionally developed marketing channels and modern value-chains that are reliably governed. 
Agriculture in SSA has been undergoing rapid transformation. A significant part of this transformation involves major changes in farmland ownership and farming scales, from small to medium and large-scale farms. Generally, households are increasing their farm sizes while others are dropping out of agriculture as the non-farm economy grows. A multiplicity of studies, including Byerlee and Deininger (2012), Jayne et al. (2016), Lay, Nolte and Sipangule (2018) and Jayne et al. (2019), across many SSA countries affirm this development. Earlier studies on farm sizes showed a Malthusian trend, whereby average farm sizes decreased in most low and lower-middle-income countries between 1960 and 2000 (Lowder, Skoet and Raney, 2016). Two key demographic processes - rising rural population densities (Masters et al., 2013) and the tendency for most people to maintain farmland ownership irrespective of their primary source of employment - created a situation where an evolution towards smaller farm sizes was inevitable (Jayne et al., 2016).

However, within the last two or three decades, several studies across many countries on the continent have shown evidence of a change in the trend towards rising, rather than shrinking, farm sizes. Jayne et al. (2016) attribute these new dynamics in farm size distribution in Africa to four main factors: changes in land acquisition regimes with the rapid rise of land markets; hikes in global food prices, which have fuelled demand in farmlands; agricultural policy reforms, which started in the 1980s and 90s but whose full effects remained dormant until the 2000s; and the increasing power of farm lobbies within the context of increasing democratisation and multiparty politics, which gave voice to farmer unions and other powerful groups. The evidence of rising farm sizes in Africa comes in three main indicators: the proportion of land under the control of medium-scale farmers; the share of land under medium-scale cultivation, and the share of production and marketed crop output accounted for by medium- and large-scale farms.

The rise of medium- and large-scale farms is driven by both stepping up (those who started small and are gradually increasing their farm sizes) as well as stepping in (those who come directly into agriculture as mediumscale farms). For the former category, regardless of the initial farm enterprise choice, with the right exposure, attitude and discipline, smallholders can increase their scale of production and commercialisation (Chapoto, Mabiso and Bonsu, 2013). Muyanga et al. (2019) observed two pathways to agricultural commercialisation involving a transition from small- to medium-scale farms (stepping up) and the emergence of investor farmers (stepping in). Amanor (2019) argues that contemporary medium-scale farmers are not the creation of market liberalisation policies, but share many similar characteristics with the commercial farmers of the 1970s, with roots in the urban civil servant and trader class fractions. In Zimbabwe, the commercialisation of agriculture was primarily determined by land access, thereby limiting it to large-scale farmers until the Fast-Track Land Reform Programme (1999-2000) opened the doors to smaller farms, though in the context of fractured state support and bureaucracy (Shonhe, 2018). Efforts towards redistributive justice in Zimbabwe also saw the indigenous elite grow through an interwoven 'bureaucratic-financial comprador' class, similar to Ghana's experience of the 1970s when the military-business class hijacked state initiatives, such as the commercialisation of rice in the north.

In the last few decades, there has been increases in the concentration of farmlands under the control of fewer people. This is exemplified by the increasing Gini coefficients ${ }^{1}$ of landholdings in some countries such as Ghana from 0.52 in 1992 to 0.65 in 2005, in Kenya from 0.51 in 1994 to 0.55 in 2006, and in Zambia from 0.42 in 2001 to 0.49 in 2012 (Jayne et al., 2014). This suggests a trajectory of concentration of land under the control of a few wealthy people in some land-scarce countries in Africa. A clearer understanding of who the main actors are is important. In general terms, customary tenure systems, which were designed to hold land in reserve for current and future generations of local people, are breaking down (Colin and Woodhouse, 2010; Yaro, 2012, 2010; Boone, 2014) and in some countries, the state is exerting its far-reaching authority in this domain (Edelman, Oya and Borras Jr., 2016; Jayne et al., 2016).

1 Originally used to measure income inequality, Gini coefficient is used here to measure the concentration of farmland ownership (see Jayne et al., 2014). 
An intensified commercialisation landscape has dominated the rural economy in SSA, which needs careful examination to tease out emerging relationships between the different actors who shift between farm categories, and the welfare implications of these trends. Several questions remain unanswered about the changing farm sizes, the spatial dynamics of expansion among different farming systems, the changes in the use of factors of production, and the institutions and political economy underlying these.

This paper sets out to investigate and present:

- A historical context of changes in agrarian transformation and farm sizes in northern Ghana.

- The changes in farm sizes over the last two decades in the study areas.

- The spatial manifestation of farms and the dynamism in farming systems.

- A characterisation of farmers involved in different farm sizes showing the use of factors of production.

\subsection{Research sites}

Two districts with vast lands and a history of commercial farming were selected for this study: the Karaga District of the Northern Region (Figure 1.1) and Builsa South District of the Upper East Region (Figure 1.2).
The selected study communities in the Builsa South District were Gbedembilisi, Weisi and Uwasi. These communities are endowed with substantial valleys, uplands and river plains for cowpea, maize and rice production. In the Karaga District, Maligunayili, Nyong and Tamalgu, which all have large uplands and valleys popular for growing groundnuts, maize, soybeans and sometimes rice were selected for the study. Both districts are migrant-receiving areas with a wide variety of urban-based farmers and agricultural traders. The lands are relatively abundant, the soils are fairly fertile, the roads are generally good, local markets are very active, mechanisation and financial services are available, and the government programmes for agriculture never elude these districts. The Builsa District has a long history of commercial farming, while that of Karaga District is relatively recent. These characteristics of the study sites provide opportunities to pose different questions on the agrarian transitions from small- to medium-scale and technological innovations.

\subsection{Methods of data collection}

This study employed a mix-method strategy of qualitative and quantitative approaches, to capture the detailed nuances from the perspective of actors and the broader picture of their actions measuring their characteristics concerning specific indicators for the main themes of this study. This assures both breadth

Figure 1.1: Map of Karaga District showing research communities

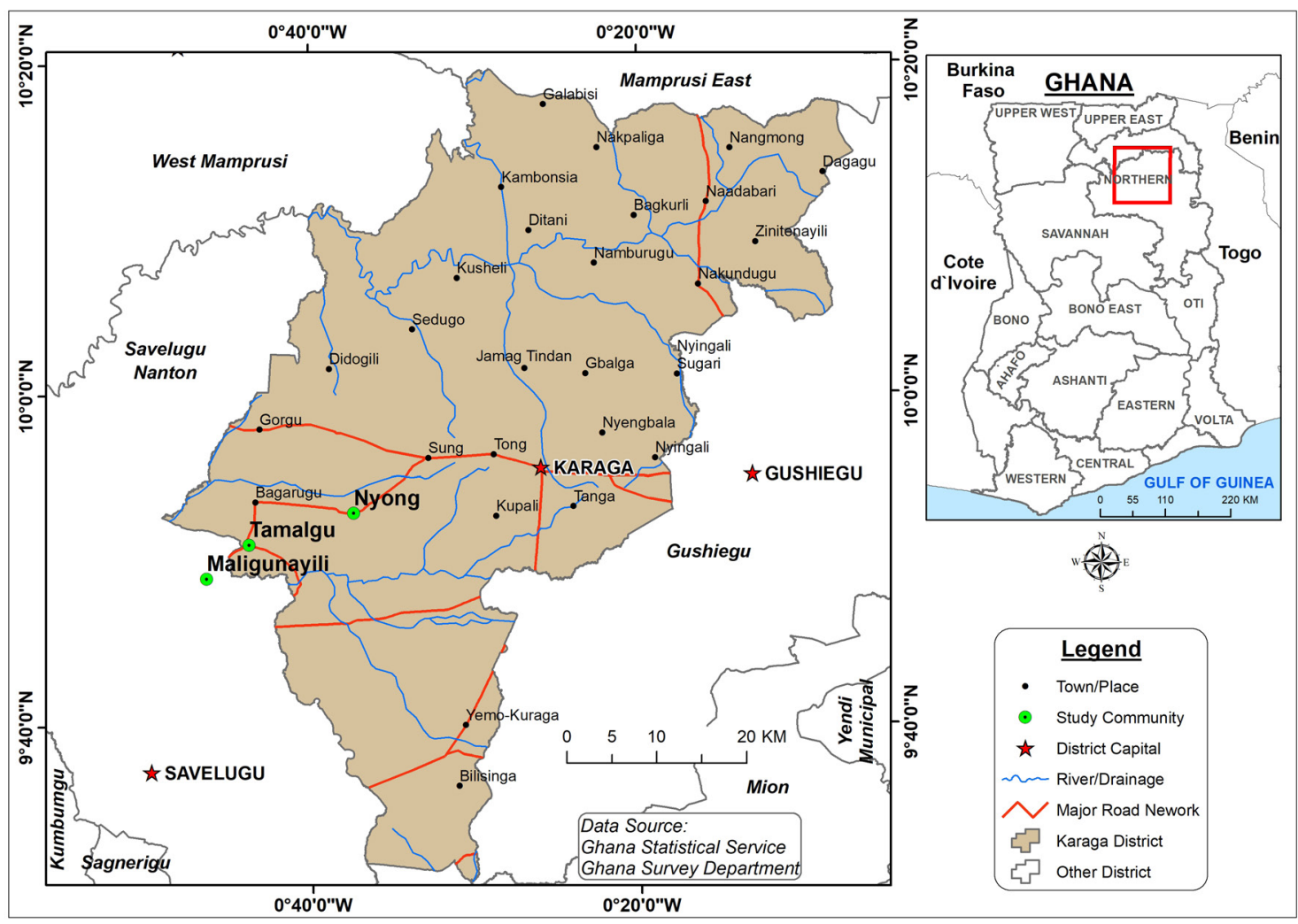

Source: @ G Ghana Statistical Services, adapted by authors 
and depth in the construction of the lives of the people studied, and the characterisation of the phenomenon of medium-scale farm changes and their socio-economic consequences for men and women. The methods employed included: a quantitative survey; life histories; farmer in-depth interviews; expert interviews; farm mapping; and focus group discussions (FGDs).

For each community, investigations began with a meeting with the chief and three elders. This was immediately followed by an interview with the chief and life history interviews with two elderly farmers from each study community. During these life history interviews, we elicited data on farm changes such as changes in farm sizes, crops cultivated, labour dynamics, and land acquisition changes that have occurred during their lifetimes. After this, separate FGDs, two for each district, were conducted with males and females. Some of the main issues discussed during the FGDs included land access arrangements, main commercial crops, technology and farm machinery changes, relationships between different categories of farmers and changes in the food security situation over the years, among others. These were followed by individual farmer interviews in the community, targeting different categories of farmers and gender groups. In all, for each district, there were four interviews with smallscale farmers, four with medium-scale farmers, two with large farmers, three with urban-based farmers. During these interviews, we collected data on agro input use, access to farmland, labour and capital as well as specific challenges confronted by different farmer categories, and specifically for the urban-based farmers, information on the main attractions of specific districts, mode of marketing output, and positive and negative implications of their presence and activities on host communities. Three interviews with tractor operators and labourers were then conducted. In these, data on the terms of engagement vis-à-vis investor farmers and local farmers were collected. Interviews with district agriculture officers (DAO) and heads/representatives of financial institutions were then conducted. In interviews with DAOs, information on main actors and their farming activities, main drivers of increasing farm sizes, category of farmers increasing their farm sizes and specific support initiatives were elicited. From representatives of financial institutions, data collected included the quantum of support for farmers, categories of farmers supported, servicing period of agricultural loans and the trajectory of support over the last two decades.

The quantitative part of the survey sampled representative farmers from two districts. The survey adopted a two-stage stratified sampling design whereby in the first stage, the six communities (Gbedembilisi,

Figure 1.2: Map of Builsa South District showing the research communities

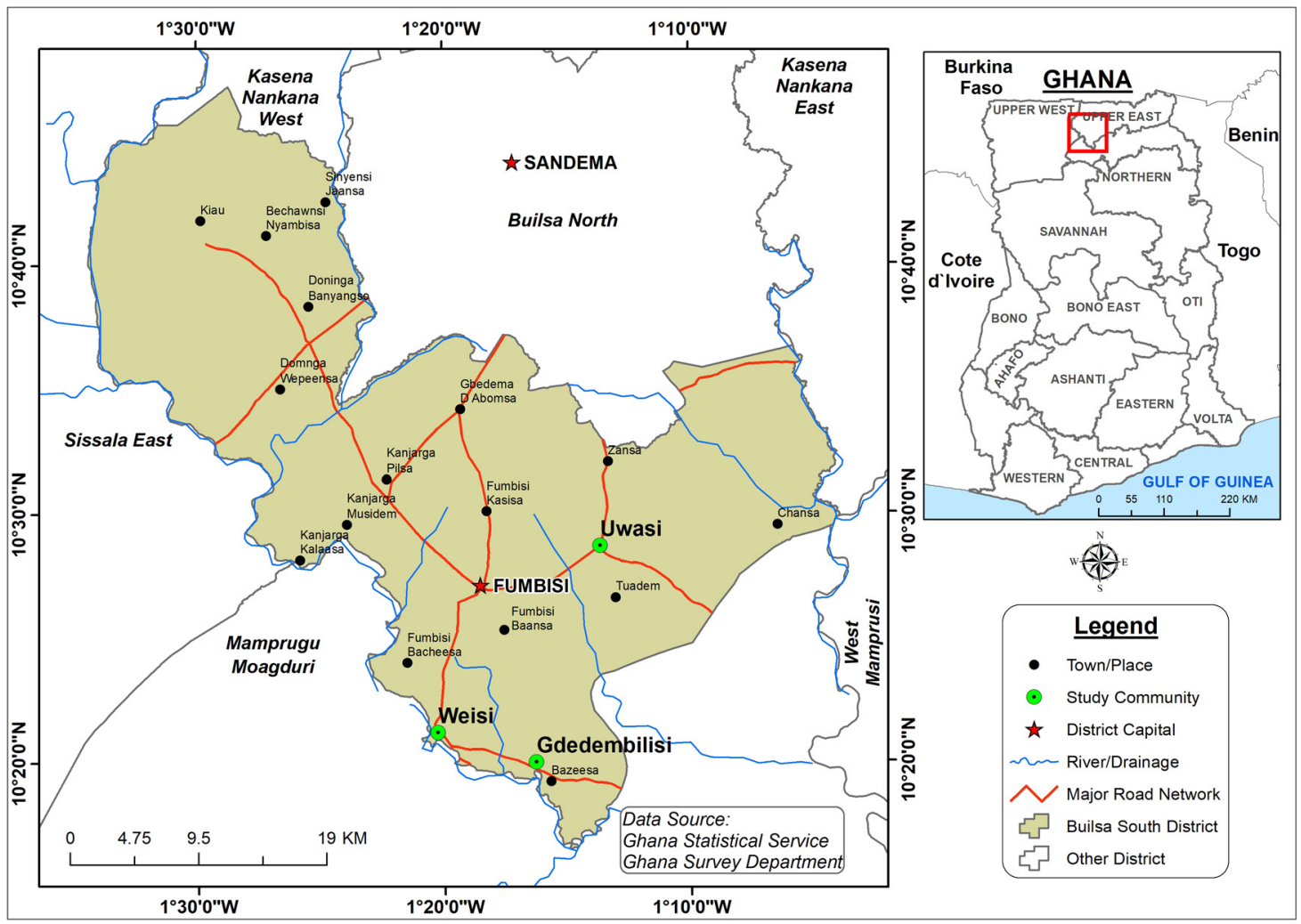

Source: () Ghana Statistical Services, adapted by authors 
Maligunayili, Nyong, Tamalgu, Uwasi and Weisi), were selected to form the primary sample units (PSUs). The PSUs were then allocated into the two districts (Builsa South and Karaga), using probability proportional to population size. A listing of farmers in the PSUs was made to form the secondary sampling units. At the second stage, every third farmer was systematically selected from each PSU to get the targeted sample size of $\mathbf{3 0 0}$ farmers. Systematic sampling was chosen over random sampling because of its simplicity, and the study also anticipated relatively lower risk of data manipulation in the data collection process. In all, just over one in every five farmers was a woman. In the Builsa South District, the survey distribution of respondents was as follows: Gbedembilisi had 26 respondents, while Weisi and Uwasi had 66 and 55 respondents, respectively. In the case of Karaga District, Nyong, Tamalgu and Maligunayili had 64, 51 and 35 respondents, respectively.

The mapping of farms was done using the Garmin $64 S$ GPS device with an accuracy of at least $3 \mathrm{~m}$. Farms in different farming systems were mapped in some selected study communities. The approach adopted was such that at least one major farmer was identified for each village (during FGDs) and once their farms (usually medium- and large-scale) are mapped, all adjoining farms are mapped as well. The mapping entails picking the central coordinates of each plot, as well as walking the perimeter to record the area of each farm. The shapefile of each mapped farm is then saved as a polygon in a geodatabase with other details of the specific farm. For each mapped farm, other attributes recorded included farmer name, migrant status, mode of acquisition of land, farm area, cropping history and crops currently cultivated, as well as photographs of crops on farms.

\subsection{Data analysis}

Post-fieldwork data cleaning, transcription of interviews and map production were executed. Analysis of quantitative data using STATA, based on the needs of evidence to answer the initial study questions, was done using simple frequencies, crosstabs, graphs, correlations. Farm productivity, farm size categorisations, farm size trends, wealth groups and other important data were generated. The qualitative data was analysed based on thematic coding used to compile attributes of each interview, in line with the data needs of the study's objectives. A careful and disciplined approach to data analysis is employed to ensure the findings' credibility. 


\section{THE HISTORY OF GAPITALIST FARMING IN NORTHERN GHANA}

The north of Ghana suffered delays in integrating into the global capitalist accumulation circuits. This was largely the result of a deliberate colonial era policy which promoted the interests of the colony (southern Ghana) through the supply of labour for mines, commercial agriculture and the nascent urban economy at the expense of the north (Dickson, 1968; Yaro, 2013). Starving the north of Ghana of infrastructure and innovation (Sutton, 1989) led to the dominance of traditional subsistence agriculture for decades, until post-independence efforts created avenues for commercial farms hijacked by an urbanpolitical-military class of investors. The abundance of flat lands and valleys suitable for growing cereals, vegetables and tubers makes it the breadbasket of Ghana. However, the deliberate assigning of the role of being a labour reserve by the colonialists (Hear, 1984), a trend which continued after independence due to the already existing spatial inequality in economic development between the south and the north, consistently delayed an internal agricultural revolution that utilises the agricultural potential of the latter region.

These notwithstanding, attempts were made at mechanising agriculture in the northern parts of Ghana, starting from 1938 with the introduction of animal draft power. The 1940s and 1950s saw the introduction of the Gonja Development Project, which was accompanied by the introduction of tractors (Ngeleza et al., 2011). These state initiatives were not resilient, as they failed miserably amidst poor technical and social considerations (Veihe, 2000). Earlier attempts by the British Cotton Growers Association to develop commercial cotton farming on the vast plains of the north were resisted by the colonial administration. Also, the naturally growing shea tree, which produces butter of great global demand, was not allowed to flourish due to the need to maintain the flow of labour southwards to the mines, cities and plantations. However, the introduction of bullock ploughs and tractors set the basis for a future yearning for these technologies, with bullock and donkey ploughing playing the initial important catalyst for commercial agriculture through increased farm sizes.

The post-independent governments aimed at modernising northern agriculture by importing tractors to achieve their objective of feeding the growing urban populations of the south. These were also seen as palliative measures to redress the colonial injustices meted out to northern Ghana. Major commercial crops, such as cotton and rice, were heavily supported by both the Nkrumah and the Acheampong regimes using different models of development (Konings, 1984). The initial socialist approaches created islands of development, while the subsequent populist strategies simply led to the hijacking of state resources by business, elite, military, and mainly urban farmers with little trickle-down effects to local rural farmers. The initial optimism shown by the high productivity and outputs from these medium and large farms, complemented by the several smallholder farmers who benefitted from state mechanisation and land clearance services, (Ngeleza et al., 2011) was short-lived as the resources ran dry and the failure to anticipate the need for agroprocessing of the resulting massive production created a demand crisis. The north of Ghana had shown its potential to feed not only Ghana but the West African region, although its poor linkage to wider markets made the first green revolution moribund.

The failure of the state's use of Neo-Fabian policies and integrated rural development projects in the 1970s ushered in the Neo-Liberal structural adjustment program, which initially decimated northern agriculture with the result being the relapse to family farms to meet subsistence needs. The removal of subsidies on agro-inputs further discouraged both rural and urban farmers, who could only survive through these support mechanisms (Yaro, Teye and Torvikey, 2018). Corrective measures to the structural adjustment program, and special initiatives to support specific crops by the burgeoning NGO community, rekindled a vibrant commercial small farm focus. Notable among these is Sasakawa Global 2000 and several others that provided subsidised improved seeds and technical support to farmers. Hope had begun to be restored to the northern farmer, which was given a spur by new state initiatives to revamp the dying food farming sector. The return to multi-party democracy provided the competition for votes which would only come with the provision of infrastructure and the return to a subsidy regime for fertilisers, improved seeds, and the deployment of extension officers. 
The restructuring of the Ghanaian economy by the Bretton Woods-sponsored Economic Recovery Programme and the Structural Adjustment Programme in the 1980s, which prescribed the withdrawal from the agricultural sector, created a void which was filled by private sector investments, especially in areas of mechanised services (Ngeleza et al., 2011; Kansanga et al., 2019a). The introduction and adoption of mechanised services resulted in increased farm sizes and shifts from growing traditional crops, such as millets and sorghum, to market-oriented crops, such as cowpea, groundnuts, maize, rice and soybean. State initiatives to support farmers also included the Agricultural Mechanisation Service Centres, which were started in 2006, different models of fertiliser subsidies and, now, the Planting for Food and Jobs programme which concentrates on improved seeds and subsidised fertilisers. Import liberalisation is credited for the influx of used tractors from advanced countries, patronised mostly by the small- and medium-scale farmers, while state importation of new tractors has made these accessible to the businesselite-chiefly classes.

An important example of agricultural commercialisation which brings together the role of the state, capitalist farmers, local small farmers, chiefs, financial institutions, and the underlying political economy relations is the development of capitalist rice farming in the Fumbisi Valley, which is well chronicled by Konings (1984). Large-scale farming in Fumbisi was carried out by wealthy urbanites who were strangers and absentee farmers. They acquired land through local customary arrangements and also benefited from bank loans and mechanisation services from the state. The initial entry was easy, as local farmers did not have the knowledge in rice farming nor the heavy equipment and investments in labour to cultivate the valleys. The state developed several bonds through costly land clearing and levelling, but these were hijacked by the rich stranger ${ }^{2}$ farmers and local chiefs to the dissatisfaction of local small farmers, often resulting in catastrophic rice fires ${ }^{3}$ destroying several thousands of tonnes of rice. The fortunes of the valleys continue to swing, as local farmers are unable to develop the rice bonds, attract markets and infrastructure, nor purchase combine harvesters, which are critical to the survival of commercial rice farming. An alliance between the elite, chiefs, the state, banks, and processing companies has become inevitable.

Technology in the form of mechanisation is accredited as the most potent explanation for commercial agriculture and farm size increases in the north over time (Kansanga et al., 2019b). Stranger/urban-based farmers are important actors in the commercialisation process, though with contradictory results for social relations at the local level. The power of the elite to push for the allocation of resources to develop infrastructure, eliminate diseases, such as onchocerciasis by aerial spraying of the blackfly habitats, and invest in technology cannot be overlooked.

The northern farmer is, today, a disaggregated group of pseudo-capitalist farmers operating at different levels of commercialisation. The evolution from subsistence to commercialised farming has not been linear, but bumpy with layered and nuanced experiences. The emerging categories of small, lower-medium, uppermedium, and large-scale farmers reflect the long historical struggle between these classes within the changing developmental discourses and paradigms.

2 Stranger farmers are non-indigene farmers, and they may (or not) reside in the communities where their farms are located.

3 Deliberately set, possibly by local farmers as a way to protest. 


\section{THE SOCIOECONOMIC PROFILE OF RESPONDENTS}

This section provides descriptive statistics of respondents, by looking at the socioeconomic characteristics of the farmers that make up the study's sample. It is important to note that although communities in northern Ghana have many similarities (such as culture and climatic conditions), there are also substantial variations (e.g. farming practices and/ or systems, norms, and other restrictions) that may influence various stages of production, marketing, and, subsequently, expansion of farm sizes over time. In Table 3.1, descriptive statistics are presented first as a pooled sample (column 2) made up of all farmers in both districts, and then by village (columns 3 to 8). From Table 3.1, the average age of the farmers interviewed is about 43 years. With the exception of Nyong, where farmers interviewed appear relatively older (about 46 years), the age variation among the other five villages/towns is minimal relative to that obtained in the pooled sample. The study's sample is made up of predominantly males, with only about one in every five of them being female, even though the ratio of females to males is slightly higher in Maligunayili and Gbedembilisi.

Over half of the farmers (60 per cent) interviewed have no formal education; with an average years of schooling of just four years (column 2). Alternatively, measuring education in levels, the respondents' level of formal education declines substantially along the education ladder. Only about one in every ten farmers has a tertiary education, and this is even lower in Weisi and Uwasi (7.6 per cent and 6.9 per cent, respectively). There are more migrants (i.e. farmers who were born outside their current community) in Maligunayili (57 per cent) and Nyong (61 per cent) than the other study villages. A sharp contrast is seen in Weisi and Uwasi, where almost nine in every ten farmers are indigenes (born in their current communities), which is followed closely by Gbedembilisi.

Farming is the main source of livelihoods for most households, which may partly have been influenced by the sample selection process due to the focus of the study. Households in the study area are typically characterised by many members - about nine, on average. Meanwhile, Nyong and Gbedembilisi have relatively larger households (11 and 10 members on average, respectively). Finally, over 90 per cent of the households in the study area have younger dependents (i.e. children below age 15).

The final part of Table 3.1 provides information about the living standards of farmers interviewed, based on their evaluation. Although the principal component analysis (PCA) approach could have been used based on asset ownership information contained in the data, we report the distribution of living standards using respondents' evaluations for two main reasons. First, the data may not have captured all assets owned by households, and so relying on an index or wealth groups created from the PCA method may not be a true reflection of the actual standard of living. Second, we argue that to some extent, "wealth" may be a relative concept, especially in rural areas, which may include ownership or satisfaction from intangible items which the data cannot capture comprehensively. Therefore, the respondents themselves may be better evaluators of their living standards. Based on farmers' ratings, there are five wealth quintiles: poorest, poorer, middle (average), richer and richest. A majority (56.3 per cent) of the farmers consider themselves to be within the average (middle) wealth group. About eight per cent each are within the poorest or richest quintile. Then, 15 per cent consider themselves in the poorer quintile, with 11.67 per cent categorised within the richer group. Comparing the living standards of farmers across the six localities, the distribution is similar, except in Maligunayili where most farmers (34.3 per cent) indicated belonging to the poorer quintile; and no farmer ranked himself/ herself among the richest quintile. In general, most of the poorest farmers are from Uwasi (17.2 per cent) and Maligunayili (14.3 per cent). 
Table 3.1: Socioeconomic profile of respondents

\begin{tabular}{|c|c|c|c|c|c|c|c|}
\hline \multirow{3}{*}{ Variable } & \multicolumn{7}{|c|}{ Percentage (mean) } \\
\hline & \multicolumn{7}{|c|}{ By locality } \\
\hline & $\begin{array}{l}\text { Pooled } \\
\text { sample }\end{array}$ & Maligunayilit & Tamalgu & Nyong & Gbedembilisi & Weisi & Uwasi \\
\hline $\begin{array}{l}\text { Age } \\
\text { (completed } \\
\text { years) }\end{array}$ & $(42.5)$ & $(41.6)$ & $(43.7)$ & $(45.5)$ & $(40.0)$ & $(40.2)$ & $(42.4)$ \\
\hline $\begin{array}{l}\text { Education } \\
\text { (years) }\end{array}$ & $(4.0)$ & $(4.8)$ & $(4.2)$ & (3.3) & $(4.4)$ & $(4.5)$ & (3.2) \\
\hline \multicolumn{8}{|c|}{ Level of formal education } \\
\hline None & 60.0 & 62.9 & 66.7 & 73.4 & 42.3 & 47.0 & 60.3 \\
\hline Basic & 25.0 & 14.3 & 15.7 & 12.5 & 46.2 & 40.9 & 25.9 \\
\hline Secondary & 5.0 & 8.6 & 5.9 & 3.1 & "- & 4.6 & 6.9 \\
\hline Tertiary & 10.0 & 14.3 & 11.8 & 10.9 & 11.5 & 7.6 & 6.9 \\
\hline Household size & $*(9.0)$ & 8.3 & 10.0 & 10.5 & 7.7 & 8.1 & 8.6 \\
\hline \multicolumn{8}{|l|}{ Gender } \\
\hline Female & 26.7 & 37.1 & 23.5 & 26.6 & 30.8 & 22.7 & 25.9 \\
\hline Male & 73.3 & 62.9 & 76.5 & 73.4 & 69.2 & 77.3 & 74.1 \\
\hline \multicolumn{8}{|c|}{ Place of birth (relative to the community) } \\
\hline Outside & 31.0 & 57.1 & 37.3 & 60.9 & 15.4 & 7.6 & 10.3 \\
\hline Within & 69.0 & 42.9 & 62.8 & 39.1 & 84.6 & 92.4 & 89.7 \\
\hline \multicolumn{8}{|c|}{ Household head's main occupation } \\
\hline Farmer & 90.6 & 90.9 & 96.1 & 89.1 & 84.6 & 89.4 & 91.4 \\
\hline Other & 9.4 & 9.1 & 3.9 & 10.9 & 15.4 & 10.6 & 8.6 \\
\hline \multicolumn{8}{|c|}{ Presence of household members < 15 years old } \\
\hline No & 7.3 & 17.1 & 3.9 & 3.1 & 11.5 & 9.1 & 5.2 \\
\hline Yes & 92.7 & 82.9 & 96.1 & 96.9 & 88.5 & 90.9 & 94.8 \\
\hline \multicolumn{8}{|l|}{ Wealth quintile } \\
\hline Poorest & 8.4 & 14.3 & 3.9 & 4.7 & 7.7 & 4.6 & 17.2 \\
\hline Poorer & 15.4 & 34.3 & 17.7 & 17.2 & 7.7 & 7.7 & 12.1 \\
\hline Middle & 56.2 & 31.4 & 70.6 & 60.9 & 50.0 & 55.4 & 56.9 \\
\hline Richer & 11.7 & 20.0 & 3.9 & 10.9 & 23.1 & 16.9 & 3.4 \\
\hline Richest & 8.4 & - & 3.9 & 6.3 & 11.5 & 15.4 & 10.3 \\
\hline
\end{tabular}

Source: Authors' own (survey data, 2020) 


\section{THE FARMING SYSTEMS OF THE TWO DISTRICTS}

Farming systems in northern Ghana have evolved, and continue to adjust to the circumstances in which farmers find themselves. The farming systems in operation are thus often influenced not only by the kinds of natural resources available - river systems, forests, soils, social organisation, and land availability - but also by tools and technologies, as well as state support and markets. Spatial arrangements, the intensity of farming, and crop distribution relative to the dwelling units are shown as a manifestation of these farming systems. Farming systems comprise farmers who organise their biophysical resources to earn a living.

The major farming systems in the Builsa District are the compound, upland, riverine, and valley systems. Only three of these; namely, upland, valley and compound systems, are discernible in the Karaga District. There are, however, differences among these farms in the two districts, due to the social organisation and community values of the different ethnic formations. While Karaga belongs to a centralised system with a nucleated settlement system, Builsa has a dispersed settlement system with an acephalous social organisation.

\subsection{Farming systems in the Builsa District}

Compound farming systems are those organised around the immediate surroundings of households. These farming systems came about from the need to have some sort of farm or garden around the farmers' dwelling to provide immediate food from early-maturing crops and vegetables. The lands within the immediate vicinity of each house were shared among the members of the family, particularly the wives of the first compound head who then passed on these lands to succeeding generations. Though they are usually controlled by women, the men in

\section{Figure 4.1: Spatial configuration of compound farms of a selected household in Uwasi}

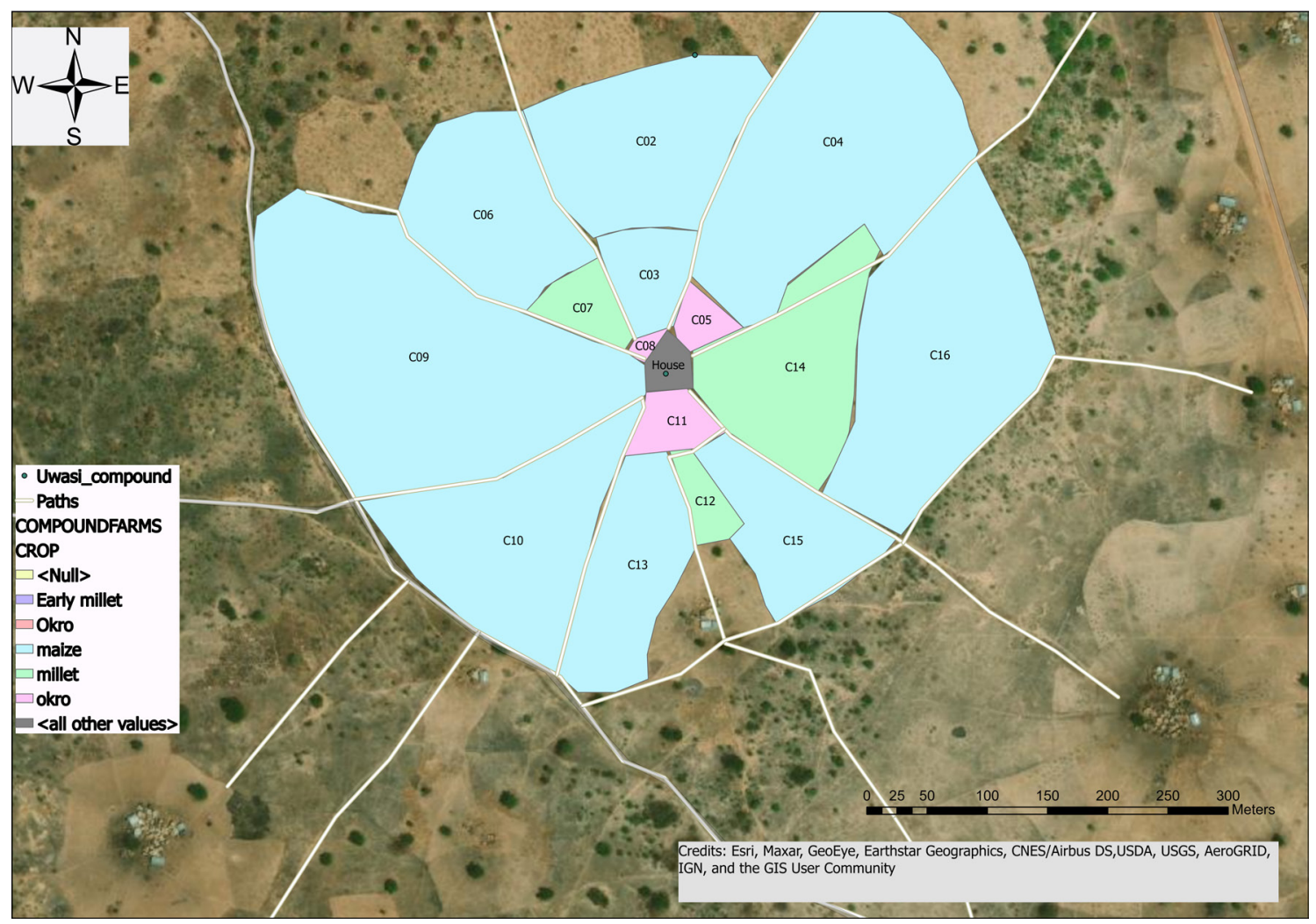

Source: Map data @ 2021 Google, adapted by author 
respective households help in cultivating the crops on the compound farm (Awen-Naam, 2019). Similar to what pertains to south-eastern Nigeria (Ugwu, 2006), compound systems are noted for both crop cultivation and livestock raising. The sowing of crops within this system is done in rings, with the inner ring used for the most important crop. In terms of crop production, the compound systems are noted for supporting a mix of beans, early millet, sorghum, and a variety of leafy vegetables. This concurs with the findings of Hunter (1967), who noted that the principal food crops grown within this farming system in north-east Ghana were early millet (Pennisetum glaucum), late millet (Pennisetum spicatum), Guinea corn (Sorghum bicolor) and groundnuts (Arachis hypogea).

There have been significant changes to the compound farming system in the last two decades, with regard to crops grown. There are communities in Builsa where millet and sorghum are no longer cultivated within the compound system. Most importantly, maize has become an important crop, replacing traditional cereals such as millet and sorghum, with most farmers now using the outer rings for the cultivation of Bambara beans, cowpea and groundnuts. Some of the reasons for this shift to maize cultivation include relatively higher yields, changes in food culture to Tuo Zaafi, which is made from maize flour, and the opportunity to use weedicides, although many of these farms are predominantly mixed-crop systems (Awen-Naam, 2019). The compound systems have reached their frontiers and have no room for further expansion. Produce from the compound farms is usually controlled by women, and these farms serve as a source of green leafy vegetables which are used to supplement the grains produced for household consumption to ensure a balanced diet. The early millet and now the short-maturing maize variety is essential for breaking the hunger season. Soil fertility in this system is supplemented with household and livestock waste. However, with the advent of subletting the care of cattle to Fulani herdsmen within the last two decades, the quantity of available animal dung has reduced considerably, necessitating the use of chemical fertilisers and even fallowing.

As the map in Figure 4.1 shows, compound farms in the district typically follow a circular structure around the household's dwelling unit. As can be observed here, the inner rings are generally devoted to vegetables, in this case, okro (Abelmoschus esculentus), denoted C05, C08 and C11 which together cover about 0.8ha. The middle sections are used for cultivating the traditionally important early millet. In this particular compound farm, millet covered an area of approximately $2 \mathrm{ha}$. The most dominant crop, in terms of coverage, is maize, which occupies the outer parts of the ring. However, maize can be seen occupying most compound farms. In such cases, green leafy vegetables are often used as boundary crops rather than occupying specific zones.

The upland systems are farther away from the dwellings of households. These systems were noted for the cultivation of a mix of Bambara beans or nuts (Vigna subterranea), groundnuts, late millet and sorghum. There are changes in crops grown in these systems, with cowpea and maize cultivation now dominating. Beyond cowpea and maize, Bambara nuts and peanuts are also cultivated within these systems. However, squirrels and other rodents pose a threat, as they often destroy Bambara nuts and groundnuts. This necessitates the continuous presence of the farmer, which is a tedious and time-consuming venture. Participation in these systems is male-dominated because of the distance travelled to and from the farm on daily basis. The exclusion of females could also be linked to their relatively limited control over resources to acquire a modern means of transport, and the heavy investments in tractor services, agrochemicals and labour. The land is not a limiting factor in the Builsa area, as vast uncultivated stretches are available to women who have financial access to cultivate them. Most women farm on upland farms that have been left fallow by the male household members, usually their husbands. Land fallowing and crop rotation are major strategies to replenish soil fertility, and are used predominantly by richer farmers who can pay for land clearing, which is expensive due to the fast-growing shrubs in the area.

The Builsa South District is traversed by the Sisili River, a tributary of the White Volta, and as such riverine farming is an important part of farmers' portfolio of resources. While the river has always been there, this farming system was not considered important some two decades ago. From the 2000s onwards, however, the riverine farming system assumed a new level of importance to farmers as it became central to the cultivation of cash crops such as cowpea and maize. Unlike the other farming systems, the riverine system allows for two cropping cycles annually. Maize is cultivated first, upon the onset of the rains around May/ June, and cowpea is then cultivated around October/ November when the floodwaters begin to recede. These systems are supported by the alluvial deposits from the Sisili River when it overflows its banks. Apart from maize and cowpea, the latter being the most important and commercialised riverbank crop since its commercial cultivation began in this district in the early 2000s, other crops in this farming system include watermelons and vegetables, such as chillies, garden eggs, okro and tomatoes. The riverine system uses 
minimal chemical fertilisers, but lots of weedicides and pesticides, and is riskier than the other farming systems as the first crops can be inundated by floods, with farmers often losing all their investments.

All the sampled farms in the riverine system are owned by indigenes. As Figure 4.2 shows, there are two, spatially discernible categories of riverine farms; those within the catchment area of the river and those slightly outside. The latter group is usually small in size and cropped with rice (plots labelled R04, which comprise approximately 1.6ha and R03, which makes up about 1.4ha), maize (R01, 2.8ha) or millet (R02, 3.6ha). These rice plots are relatively small compared to those in the developed valleys, and are predominantly cultivated by women with most of the produce used for household consumption. The farms are within the catchment area of the river system's floodwaters. Thus, they are often cropped twice a year with the minor crop, which is usually maize, harvested as soon as possible to enable the main cash crop, cowpeas, to be planted immediately after the flood waters recede. The few exceptions, including plot R07 (cowpea, 8ha), are often divided into sections with a portion planted with watermelons (Citrullus lanatus). Some of these plots R10 (cowpea, 7.7ha), R12 (cowpea, 4.5ha), and R13 (cowpea, 6.5ha) - having been cultivated for the past ten years, seeing additional expansions in area in the last 5 years. The latter plot, R13, was cropped with early maize until 6 years ago, when the farmer began to use it for cowpeas instead.

Until two decades ago, the valley farming system was not attractive to native farmers as it was underdeveloped. The indigenes did not see the potential of the valley in commercial rice farming until the emergence of stranger farmers. The valley farming system is noted for the cultivation of rice only, usually on a commercial scale, and these systems are capitalintensive as farmers need tractors, planters, combine harvesters and agrochemicals to participate fully. Further, in some communities, the valleys are far from the settlements, which necessitates motorised means of transportation. These factors thus largely limit the extensive participation of native farmers in the valley system, with strangers and richer indigenes who can command the necessary resources to invest in farming dominating the system. Due to agitations by the youth, culminating in the arsons from the previous year, many stranger farmers have moved to other communities, thereby accounting for the low numbers observed in the study's mapping.

The Valley One flood recession scheme covers 250ha of land, and was developed under the Northern Rural Growth Programme and funded by the African Development Bank and the International Fund for

\section{Figure 4.2: A sample of riverine farms along the banks of River Sisili in Weisi}

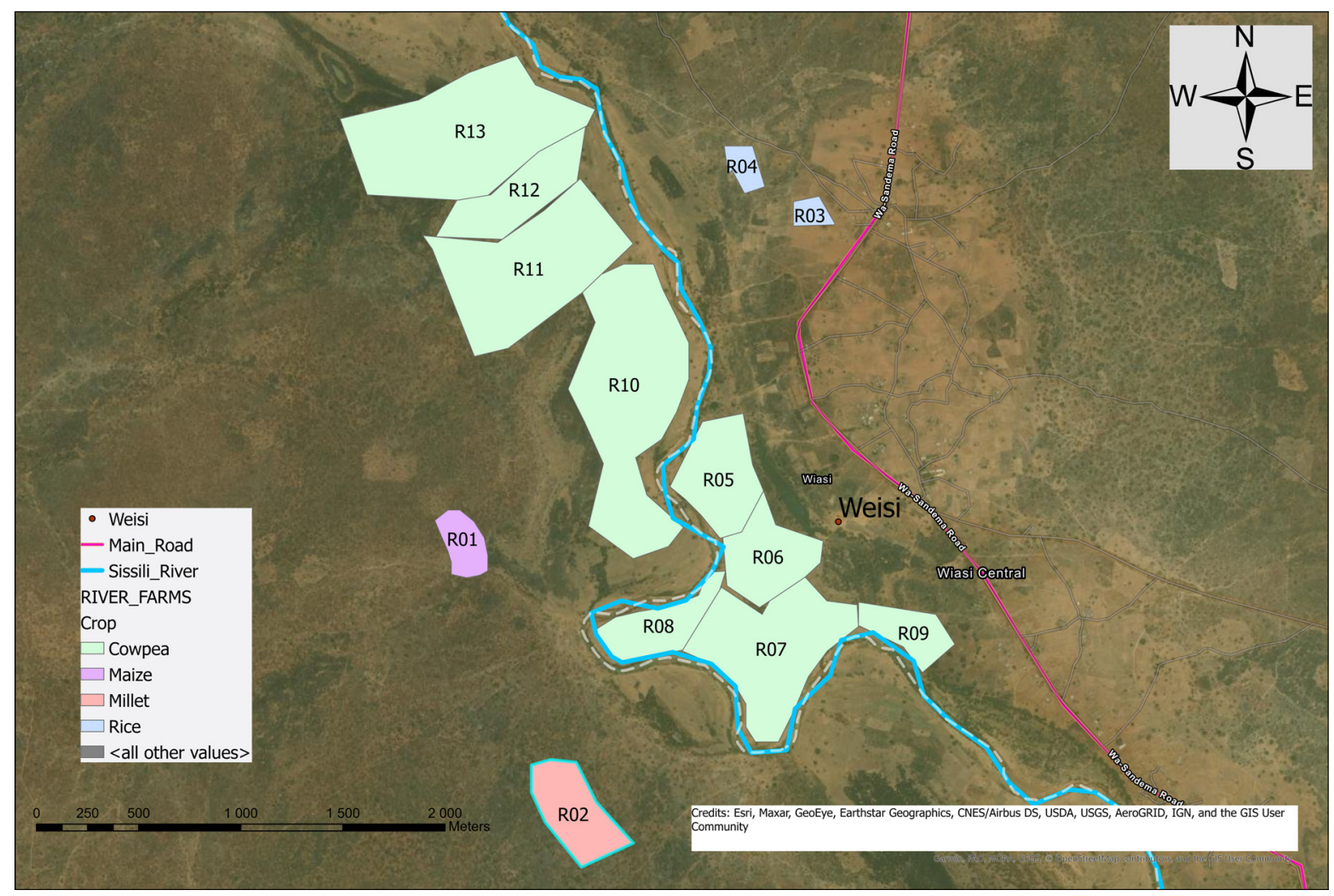

Source: Map data @ 2021 Google, adapted by author 
Agricultural Development. In contrast to the other farming systems, which are controlled and accessed through families, valley lands are within the domain and control of the chief and the earth priest due mainly to their commercial value, and the fact that they were not claimed through first cultivation by the fathers of the present farmers (Awen-Naam, 2019). It is pertinent to note that control does not mean ownership. That is, the chief could neither sell nor prevent community members from using it.

Farms in the valleys are relatively larger and more commercialised than the other systems (see Figure 4.3), with the average size being about 16ha. The developed parts of the valley are organised in bonds of about 8ha each. The development of rice valleys into bonds is important because not only does bonding help water management in fields, but it also prevents the washing away of fertiliser and helps farmers traverse their fields even in waterlogged conditions. Except for the farm labelled V08 (23.5ha), which is owned by a corporation - HABKAY Farms - all others are individually-owned. While Figure 4.3 suggests that only four of the rice farms in Valley One are owned by stranger farmers, it is pertinent to note that most of the owners of some of the other fields are not ordinarily residents in the Gbedembilisi community. While the largest rice farm is owned by the chief of the community (V05, 49.4ha), other major farmers in Valley One include members related to the chief's household, such as his brother who is a United States (US) Army Officer and resident in the US (V01 and V02, together constituting 35.6ha) as well as other relations (V03). Indications on other farms (V09 and V10) suggested that they belonged to the chief, although this could not be independently verified. With regard to the profile of the stranger farmers, the owners of V07 and V12 (17ha) hail from Navrongo, the latter of which is a retired military officer, while the owner of V13 (17.8ha) hails from Sandema. The owner of the plot labelled V16, although a native of Gbedembilisi, is mainly resident in Accra.

\subsection{Farming systems in the Karaga District of the Northern Region}

In the Karaga District of the Northern Region, three main farming systems are discernible of which one is dominant. These are the compound farm, the upland farm, and the valley farm systems. The compound and valley systems are not often cultivated, due to problems of livestock in the case of compound farms and marketing problems in the case of the valley system. This leaves the uplands as the primary farming system, which has gained commercial status due to the introduction of soya bean cultivation in addition to the age-old groundnut and maize crops. This area has had a reputation for growing groundnuts since the colonial days.

\section{Figure 4.3: Valley farms in the Gbedembilisi}

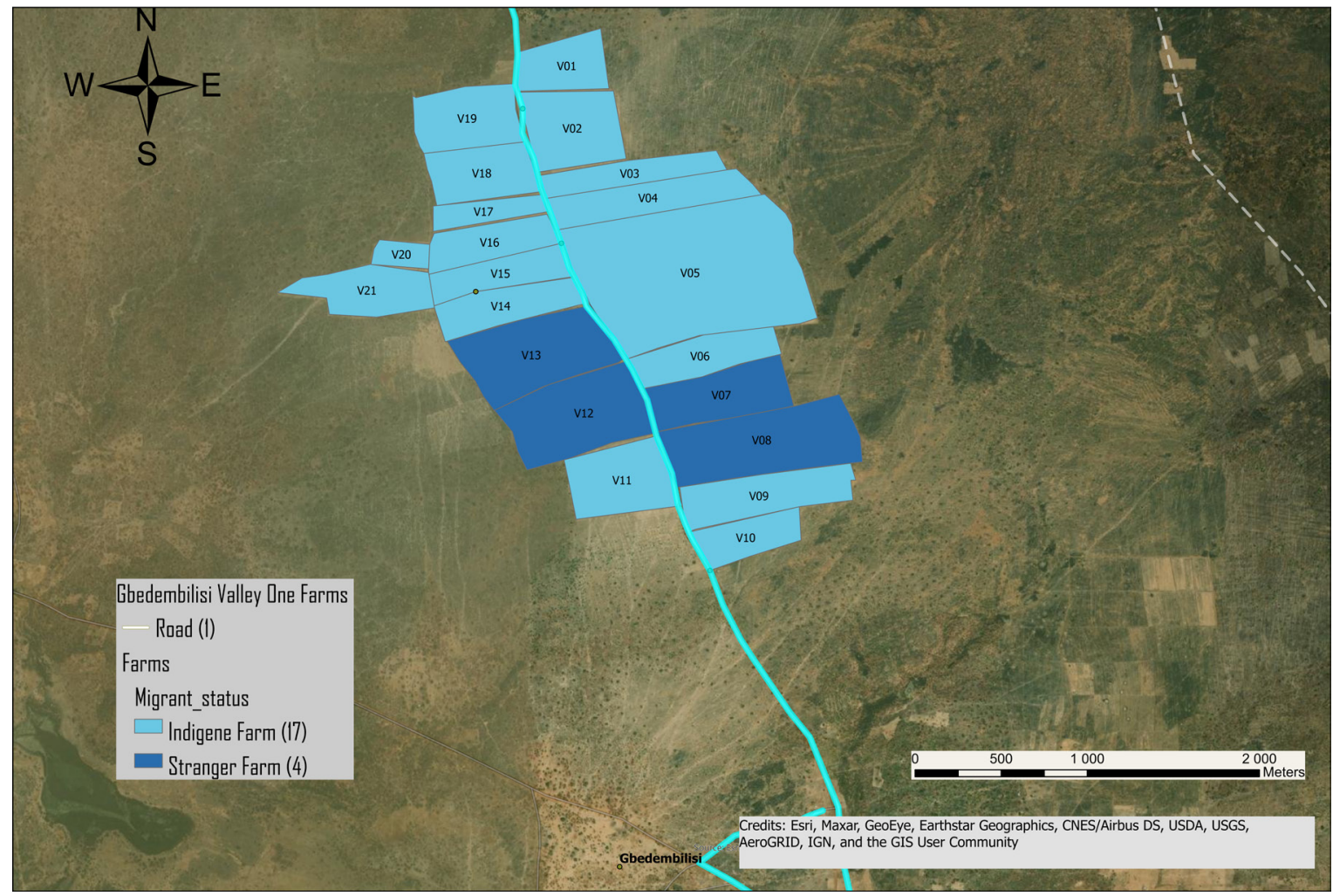

Source: Map data ( 2021 Google, adapted by author 
The compound farms are much smaller than those in the Builsa area, because of the closeness of the houses to each other - a nucleated settlement pattern is discernible. In local parlance, these are known as sanbanpua. Maize, millet, sorghum, and a few leafy vegetables were the crops grown prior to these recent changes in the last two decades. Today, crops grown include chillies and leafy vegetables, which must often cordoned-off with fences due to livestock destruction. As a result, farmers who cannot afford fences have abandoned these farms to livestock grazing. The cultivation of these plots is contingent on the strict control of the chief in promulgating and enforcing the tethering of the goats and sheep that destroy compound farms. Also, when a few farmers cultivate while others do not, it is difficult to galvanise a common strategy for animal control, thereby generating conflicts. Fencing these farms has become common, but that means crops with higher values, such as chillies, are mixed with some cereals and vegetables for household consumption.

The uplands stretch from very close to the community, to farms several kilometres away, forming a continuum. The main crops grown include maize, peanuts and soybeans, and of lesser area coverage are Bambara beans, cassava, cowpea, millet, sorghum, traditional beans and yams, which are mostly used for household consumption. Many of these which used to be cultivated widely are no longer popular among farmers, which can largely be accounted for by the increasing use of weedicides, as alluded to in the excerpt:

"We do not cultivate it [red sorghum] any longer. We used to cultivate it but because of the chemicals, if you cultivate it, it will all die. We used to practice mixed cropping. If you cultivate peanuts, then you sow some sorghum and millet on the same land. Now if you spray the peanut farm with the weedicide, the millet will all die. The weedicides are not good for millet. It is maize, soya beans, rice and peanuts that have their weedicides. But we have not yet received weedicide for sorghum and millet. We used to practice mixed cropping but now it is no longer practised except on some small farms" (male farmer, FGD, Nyong, August 2020).

The increasing use of herbicides and weedicides is changing how farming is done and reducing the diversity of crops, significantly changing cropping systems. Vegetables must now be cultivated separately, with weed control mainly performed manually with a machete and hoe. The Karaga District is famous for early commercialisation and mono-cropping of mainly commercial crops, like peanuts, maize and soybeans. Of special interest is the increasing popularity of soybeans as synonymous with the name Karaga, as

\section{Figure 4.4: Upland farms in Nyong showing the different crops cultivated}

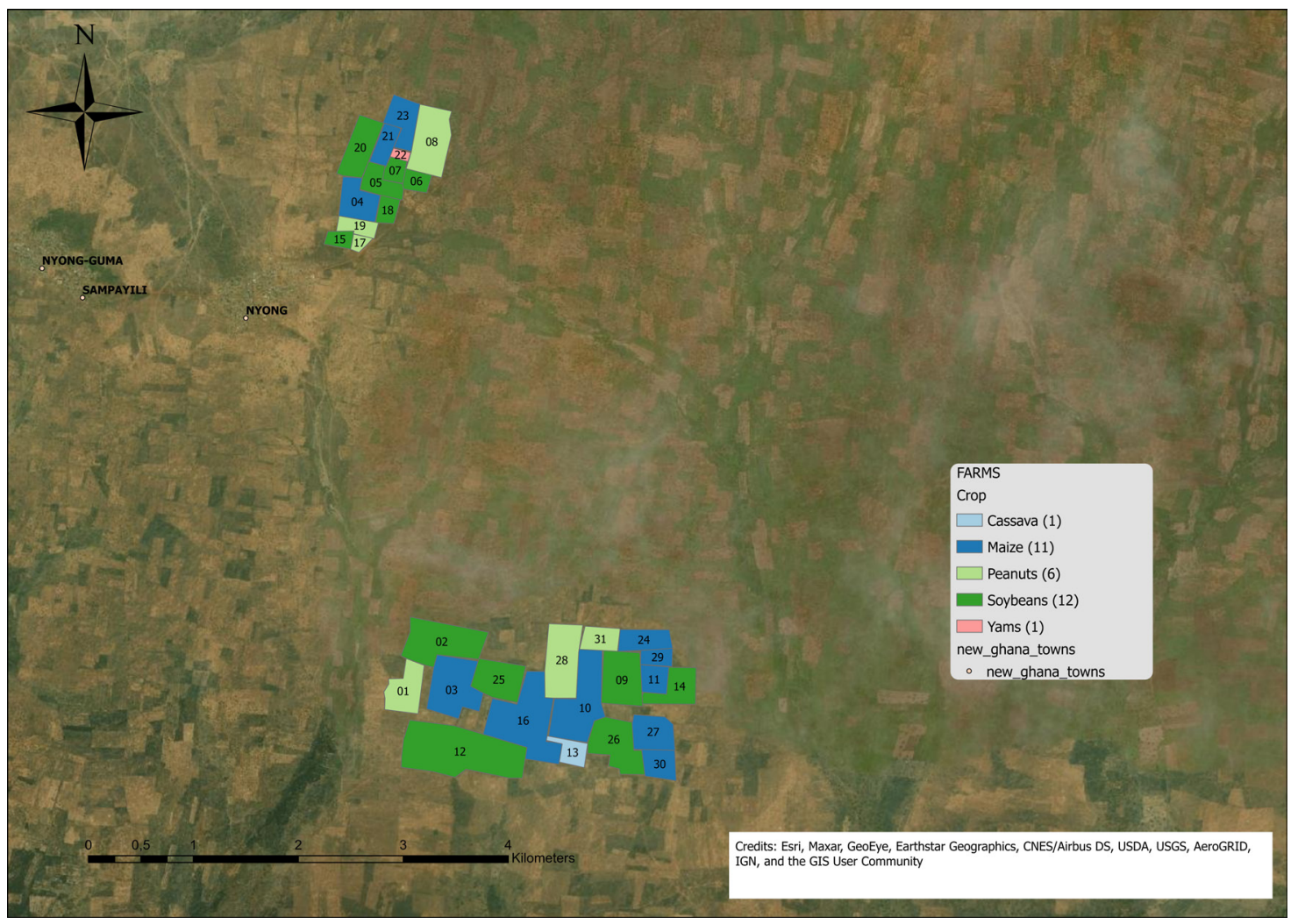

Source: Map data @ 2021 Google, adapted by author 
all categories of farmers cultivate it. Its lucrativeness is borne out of the relatively lower cost of production and higher market demand.

In the upper sections of Figure 4.4, the cultivation on farms labelled 04 (maize, 10.5ha) and 05 (soybeans, 9.7ha) was started by a native in 2010. Crops are routinely rotated to maintain soil fertility, as well as prevent weeds from developing resistance to specific weedicides. Plot 08 (peanuts, 21ha) is also owned by a native who also cultivates 1.6ha of yam (plot 22) as well as Plot 23 (maize, 9.7ha). In the southern sections of Figure 4.4, Farms 09 (soybeans, 17ha) and 10 (maize, 21ha) are owned by a migrant farmer who started cultivating these lands as far back as 2010. The same farmer also operates Farm 28 (peanuts, 19.4ha) and a smaller farm (cassava, 2.4ha). Other large farms within this section of the map include Plot 12 (soya beans, 25.9ha), owned by a native, as well as Plot 16 (maize, 25.1ha), owned by a stranger farmer who is resident in Tamale. The oldest farms in this enclave are Plots 02 (soya beans, 17.8ha) and 42 (maize, 17ha), which are both owned by natives of Nyong.

The valley farming system in the Karaga District is used predominantly for the cultivation of rice located in the lower-lying areas. While commercial rice production in the district is important, it is not as significant as in the Fumbisi Valleys of Weisi and Gbedembilisi. This notwithstanding, it serves as a critical source of commercial farming to complement soybean production. The valleys were more actively cultivated in the 1970s compared to now. This is due mainly to marketing challenges and the lucrativeness of the alternatives, soybean and groundnuts, which have a lower cost of production with relatively accessible tractor services compared to the scarcity of 4-wheel tractors and combine harvesters for rice farming.

Interviewees explained that, in the 1970s, wealthier stranger farmers trouped to the valleys to cultivate very large rice farms which were in the order of about 40 to 1,200 ha, similar to the accounts of the so-called 'agricultural years' of 1972 to 1974 (Konings, 1981). Most of these very large farms collapsed during or after the overthrow of the Acheampong regime. In more recent times, with the introduction of the government's Planting for Food and Jobs Programme, commercial rice cultivation in the district is being reinvigorated. However, while there was significant state support for commercial farmers in terms of subsidised loans and machinery to augment local resources in the 1970s (Shepherd, 1981; Owusu 1975), the Planting for Food and Jobs programme does not seem to provide financial and machinery support except for fertilisers and seeds. Under the current programme, local and stranger commercial farmers are having to rely on their limited resources to undertake these huge investments. The consequence is that commercial rice production is not stable over the years. Field visits showed vast uncultivated rice fields with wild rice growing in many places, a situation which the chief attributed to low returns from the previous years and the huge cost of harvesting.

For the two districts, the compound and upland farming systems used to be the most vital for farming households' food security. This has gradually shifted to riverine and valley farming systems, with specific crops such as cowpea, maize and rice gaining greater economic value for farmers in the Builsa area. Meanwhile in Karaga, the uplands are the main commercial farming zones. The most important new resource is the riverine valley whose fertility is replenished annually by floodwaters making the use of external inputs, especially chemical fertiliser, minimal, while guaranteeing higher outputs. 


\section{CHANGES IN FARM SIZES IN THE COMMUNITIES - 2000 TO 2020}

Using a five-year interval and the percentage of farmers with varying farm sizes, Figure 5.1 presents the changing farm structure based on farm size (measured in hectares) for the last two decades. In this report, farmlands up to 10 acres (4.04ha) are categorised as small-scale, 11-50 acres (4.45-20.23ha) as lowermedium, and 51-100 acres (20.64-40.46ha) as uppermedium-scale. Farmlands beyond 100 acres (40.46 ha) are categorised as large-scale.

From Figure 5.1, two trends are obvious - a rise in medium-scale farming (particularly lower-medium); and a decline in the small-scale farming category. Thus, the percentage of farmers operating on a lower-medium scale has more than doubled between 2000 and 2020. At the same time, the percentage of farmers operating on a small scale has declined by almost half (from 76.4 per cent in 2000 to 36.3 per cent in 2020.

Figure 5.1: Changing farm structure (2000-2020)
As the rise in medium-scale farming is primarily driven by lower-medium-scale farming activities, growth rates are closely studied. Here, even though a consistent increase in the proportion of lower-medium-scale farms can be observed in the last two decades, the highest growth of about 34 per cent was experienced between 2000 and 2005; where the percentage of lower-medium-scale farmers increased from 20.9 per cent (2000) to 28.1 per cent (2005).

Furthermore, in Table 5.1, the changing structure of farm-scale (size) is presented by locality to identify any village-specific trends during the reviewed period.

Generally, there is a similar rise in medium-scale farming in the six villages, with very little variation. Within the reviewed period, a consistent rise in medium-scale farming activities can be observed in Gbedembilisi and Weisi; ${ }^{4}$ and an associated decline in the proportion of

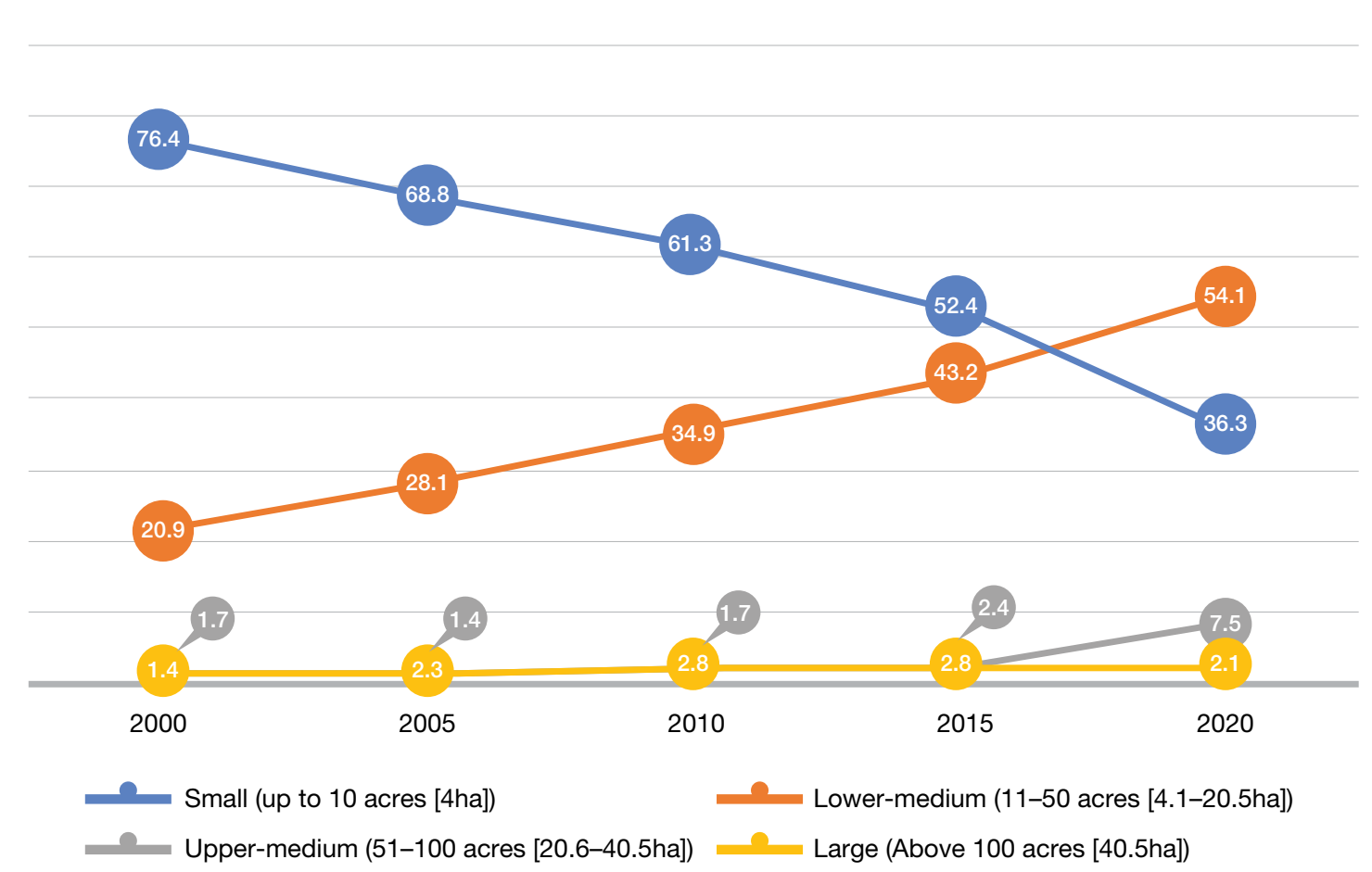

Source: Authors' own (survey data, 2020)

$4 \quad$ Note that in Weisi, the percentage of upper-medium scale farmers fell marginally, by 1.6 per cent, between 2000 and 2005. 
small-scale farms. In Tamalgu and Nyong, the rise in medium-scale farming is most noticeable between 2005 and 2020. It is also worth noting that the biggest rise in medium-size farming is seen between 2015 and 2020 in Gbedembilisi, where the proportion of lowermedium-scale farms increased by about 23 per cent, from 46 per cent to 69 per cent. This is mainly due to the increasing lucrativeness of rice farming, which began receiving state support as a result of the high import bill on rice.

Weisi is an older famous farming community with a history of migrant farmers just as Nyong, hence the higher percentages of upper-medium and large farms even 20 years ago. Uwasi, despite having vast lands, is made up of mostly valleys which require lots of investments, hence their growth is limited until the local population has the technology to engage in rice beyond the household subsistence level. Uwasi, which historically has been orphaned in the Builsa area, registered the highest number of upper-medium farms, as migrants move from conflict-ridden old production areas of Weisi to these unexplored areas, bringing with them farm machinery.

Finally, the gender variation in changing farm size (scale) is presented in Figures 5.2 and 5.3. The rise in medium-scale farming is evident among both female and male farmers, and this is also driven by lower-

Table 5.1: Changing farm structure by locality (2000-2020)

\begin{tabular}{|c|c|c|c|c|c|}
\hline & 2020 & 2015 & 2010 & 2005 & 2000 \\
\hline & \multicolumn{5}{|c|}{ Maligunayili } \\
\hline Small & 60.6 & 69.7 & 72.7 & 72.7 & 75.8 \\
\hline Lower-medium & 36.4 & 27.3 & 24.2 & 27.3 & 24.2 \\
\hline \multirow[t]{2}{*}{ Upper-medium } & 3.0 & 3.0 & 3.0 & - & - \\
\hline & \multicolumn{5}{|c|}{ Tamalgu } \\
\hline Small & 39.2 & 51.0 & 64.7 & 74.5 & 72.6 \\
\hline Lower-medium & 56.9 & 45.1 & 33.3 & 23.5 & 25.5 \\
\hline \multirow[t]{2}{*}{ Upper-medium } & 3.9 & 3.9 & 2.0 & 2.0 & 2.0 \\
\hline & \multicolumn{5}{|c|}{ Nyong } \\
\hline Small & 20.0 & 31.7 & 41.7 & 55.0 & 55.0 \\
\hline Lower-medium & 65.0 & 58.3 & 48.3 & 36.7 & 36.7 \\
\hline Upper-medium & 11.7 & 3.3 & 3.3 & 1.7 & 3.3 \\
\hline \multirow[t]{2}{*}{ Upper-medium } & 3.3 & 6.7 & 6.7 & 6.7 & 5.0 \\
\hline & \multicolumn{5}{|c|}{ Gbedembilisi } \\
\hline Small & 11.5 & 50.0 & 57.7 & 73.1 & 96.2 \\
\hline Lower-medium & 69.2 & 46.2 & 38.5 & 23.1 & 3.9 \\
\hline Upper-medium & 15.4 & - & - & 3.9 & - \\
\hline \multirow[t]{2}{*}{ Large } & 3.9 & 3.9 & 3.9 & - & - \\
\hline & \multicolumn{5}{|l|}{ Weisi } \\
\hline Small & 29.7 & 48.4 & 51.6 & 62.5 & 79.7 \\
\hline Lower-medium & 59.4 & 46.9 & 45.3 & 34.4 & 17.2 \\
\hline Upper-medium & 7.8 & 3.1 & 1.6 & 1.6 & 3.1 \\
\hline \multirow[t]{2}{*}{ Large } & 3.1 & 1.6 & 1.6 & 1.6 & - \\
\hline & \multicolumn{5}{|c|}{ Uwasi } \\
\hline Small & 55.2 & 70.7 & 84.5 & 81.0 & 89.7 \\
\hline Lower-medium & 37.9 & 29.3 & 15.5 & 19.0 & 10.3 \\
\hline Upper-medium & 37.9 & - & - & - & - \\
\hline Large & 1.7 & - & - & - & - \\
\hline
\end{tabular}

Source: Authors' own (survey data, 2020) 
medium activities in both groups. However, the rise among female farmers is relatively gradual (Figure 5.2) compared to that among their male counterparts (Figure 5.3). Even though all large-scale farmers are male, the percentage of farmers with farmlands categorised as large scale has been stable over the last 15 years (see Figure 5.2).
As Figures 5.2 and 5.3 show, compared to their male counterparts, women are conventionally mainly smallscale farmers. This can be attributed to a number of factors. First, they often concern themselves primarily with the sustenance of the household and thus cultivate sizes to meet household food needs. Second, this category of farmers is limited by economic reasons,

Figure 5.2: Changing farm structure among female farmers (2000-2020)

\section{Female farmers}

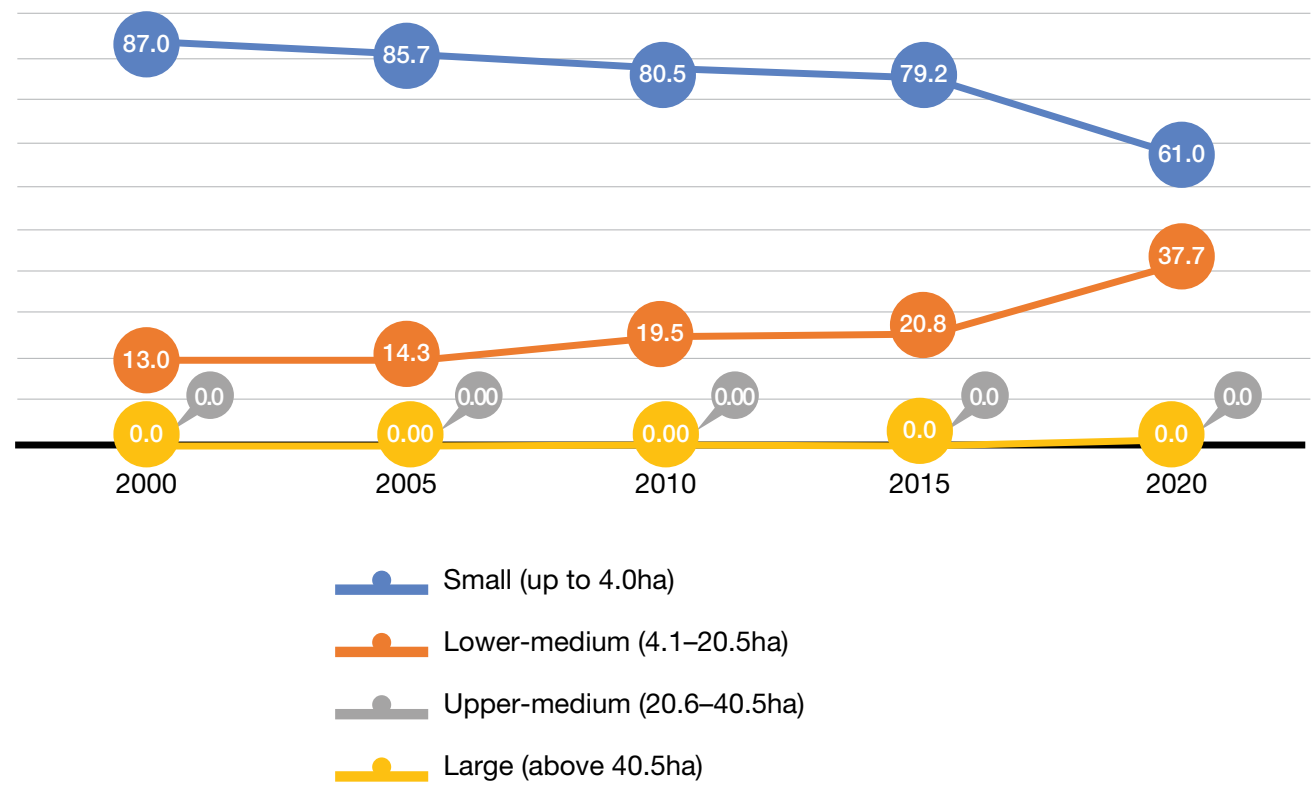

Source: Authors' own (survey data, 2020)

Figure 5.3: Changing farm structure among male farmers (2000-2020)

\section{Male farmers}

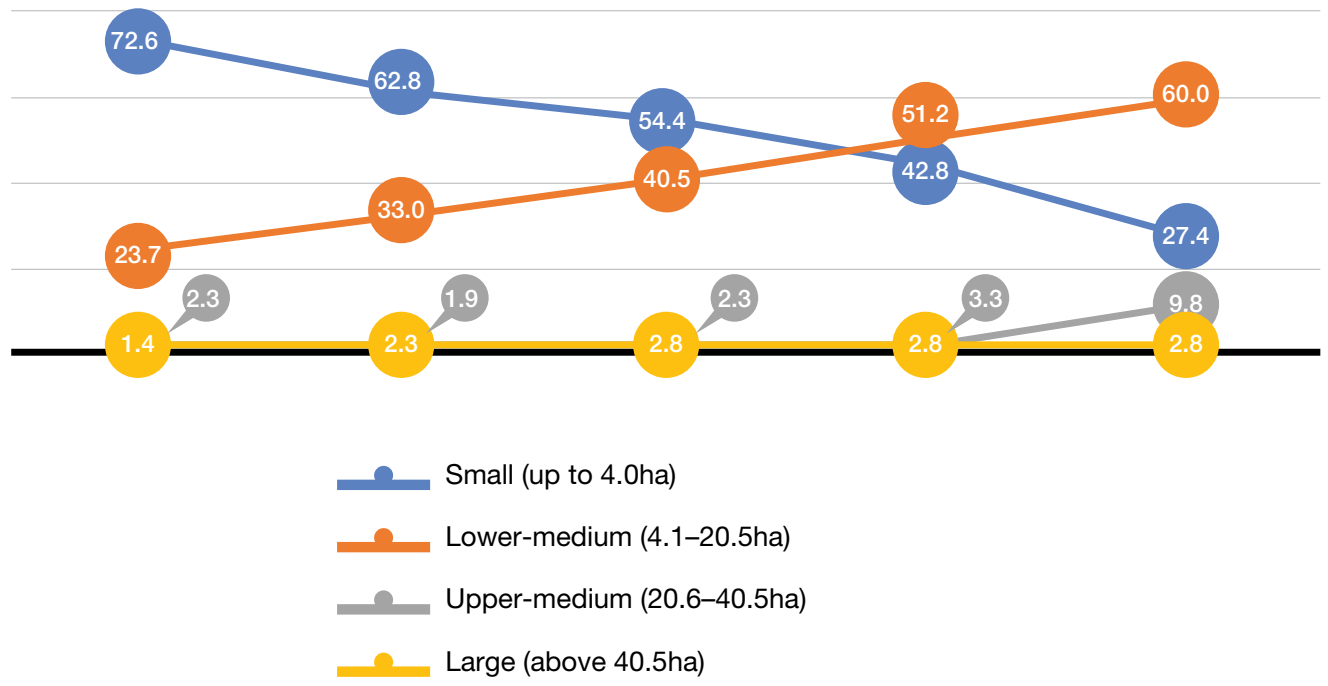

Source: Authors' own (survey data, 2020) 
due to their marginalisation in the control of productive household and community resources. While men tend to control most household resources, and thus have the wherewithal to maintain or increase their farm sizes, women are limited in their ability to command financial or physical resources to cultivate expand farms. Third, women tend to cultivate smaller farm sizes due to traditional land tenure systems which limited their ability to access large tracts of land for farming purposes, compared to men. Unlike their male counterparts, who can access any idle community farmlands, females are expected to do so only through male members of their household. It is, therefore, unsurprising that the rate of change in farm sizes is slower among women than among men, as many female farmers take over older farms of men. The exceptional cases are usually those who co-own farms with their male spouses. Two illustrations of such women are presented below, who have become medium-scale farmers as a result of their male spouses' unavailability through migration, ill health, or death. In the case of Shawana, a 48-yearold mother of eight whose husband suffered a stroke, though the family's original farm has reduced in size, she is still able to maintain nearly 7ha with the help of older sons, while also engaging in trading farm produce. Her husband is generally restricted to occasional supervisory visits to the farm.

Another female farmer explains the arrangement she has with her husband:

"We [respondent and her husband] cultivate 70 acres [28.3ha] in total; 20 acres [8.1ha] of peanuts, 30 acres [12.1ha] of soybeans, and 20 acres [8.1ha] of maize. My husband lives in Accra so he does not farm, but gives me money to farm. I am the one responsible for everything until it is matured for harvesting, then he will come and count the bags. When it is harvesting time, he will be at home, but at the beginning of the farming season, he will run to Accra. He usually shares the produce such that if there are 10 bags he will keep 6 for himself and leave 4 bags for me" (excerpt from an interview with an upper-medium scale female farmer, Nyong, August 2020).

The excerpt above shows the power dynamics at play at the household level, whereby couples collaborate to cultivate large farms. There are several layers to this power structure. For instance, the wife uses the husband's plot and name to register for fertiliser coupons and must find a male relative to purchase with the coupons when the time comes. To ameliorate the asymmetrical power structure, she cultivates peanuts - which do not require fertiliser application - without the husband's contribution and thus the latter does not have any share in this. The produce is shared such that the husband takes a larger proportion and leaves 40 per cent to the wife and children.

The dynamics of the changing farm size for men has been one of the clear and significant increases in the proportion of lower-medium-scale farms and a concomitant consistent decline in the proportion of small-scale farms between 2000 and 2020. 


\section{FACTORS OF PRODUCTION: USAGE AND DYNAMICS BY DIFFERENT CATEGORIES OF FARMERS}

In this section, the dynamics and forms of access and usage of production factors employed by the farmers in the two areas are examined. It shows the differential or similar patterns by farmers of different farm sizes, socio-economic and locational characteristics. The literature argues that smaller farmers are less likely to use modern inputs and mechanisation compared to larger ones (Houssou and Chapoto, 2014; Kansanga, 2017), although many also argue that small farmers are more efficient than their larger counterparts (Netting, 1993). We argue that though scale is important in determining what equipment farmers buy, it does not determine what equipment they use due to the divisibility of mechanised services through rental markets. Also, the use of agro-inputs might be more influenced by the type of crop, soil characteristics, labour availability and general market conditions than the often argued for modernised large farms, versus traditional small farms. The level of usage of modern farm inputs is not necessarily dependent on farm size/ scale of operation, but rather on the functionality within the commercialised agrarian landscape.

\subsection{Land tenure systems and access}

Land is a critical resource in every farming system, as it defines the types of crops and scale of production of farmers. The two districts studied have different land tenure systems as described below.

In the Builsa District, there are multiple types of landholding systems, but the land is mostly controlled by families under the overall tutelage of the earth priest. This is supported by the voice of one of the chief's elders in Weisi that: "It is the earth priest who takes care of the land. The chief is responsible for the people and not the land. The land is controlled by the earth priest, as he performs sacrifices on our behalf and there is a central earth priest who controls all of them" (excerpt, elder Weisi, August 2020). Modern interpretations now ascribe some role to the chiefs of the communities, too, about certain categories of land, including those developed by the state such as the rice bonds. Chiefs in this area were colonial creations to control development and the transfer of labour to the south of Ghana.
Family lands are those that are passed on from generation to generation, and were cultivated by the first settlers. At the time of the first settlers, these lands were allotted to families by the earth priest, who is tasked with the responsibility of allocating land to community members. What was needed then to access land by community members were cola nuts and a fowl. Once a community member identified an area to be cultivated, the earth priest was contacted, and a fowl was killed to indicate a transfer of control over that parcel of farmland from the earth priest to that member of the community. Pito, a local drink made with sorghum, was then used to cleanse the blood of the fowl slaughtered by the member after the first harvest. These lands, once transferred to families, became family-controlled lands. This procedure applied to all lands within the four farming systems in the Builsa area. Most communities in Builsa are divided into sections, with the land in every section under the control of a sectional earth priest who are, in turn, under the control of a central earth priest.

Indigenes in need of more land can request it from other members who are underutilising their family lands. This is often done without involving the earth priest or community chief. The request for additional farmland from another community member does not mandate any specific items to be given before such a request is granted. Money and some parts of the farm produce are, however, expected from the farmer at the end of the harvest, as observed by one farmer: "There are no specific items that are taken, but I give some money to the owner of the land before cultivating it. Additionally, some of the farm produce is given to the landowner after harvesting" (excerpt, male farmer Weisi, August 2020). This arrangement does not lead to a permanent transfer of control to the new farmer, but is only temporal as the land can be taken away anytime the original farmer wants to farm.

With modernisation comes the waning of the earth priest's powers in allocating land to members of the community. Lands that are not under the control of any family are supposed to be controlled by the earth priest. However, this is no longer the case, as the power of the earth priest in controlling unclaimed lands 
is being contested by some chiefs. A chief's role in the land tenure system in Builsa is to serve as a witness in any land transaction, such that he can resolve any future problems. For instance, the valley lands, which are supposed to be controlled by the earth priest, are now under the control of some chiefs, which often results in struggles over control of valley lands between the earth priest and the chief in some communities.

There are also gender differences in access to land in Builsa. Women do not own land in this region, and are supposed to have access to farmland either through their husbands or fathers. Generally, female farmers access farmland through their husbands or their husbands' families. Fathers can give farmlands to their unmarried or divorced daughters. In the absence of a father, a female who is interested in farming can obtain farmland from her brothers. There are, however, instances where female farmers can obtain farmlands from the earth priest or the chief of the community. This is usually the case of the valley, upland and riverine lands. In any of these instances, the female farmers are led by a male to ask for farmland, as it is not a normal practice for the female to approach the earth priest or chief by herself. This confirms the observation of Antwi-Agyei, Dougill and Stringer (2015) that women and migrant farmers are often discriminated against in farming spaces in rural Ghana. This practice often limits the accumulation process of women and denies them access to collateral for bank loans to expand their farm enterprises, as their use of the land is temporal and can be terminated at any time.

Access to farmlands by migrant farmers depends on who controls the farmland in question. If it is family land, they must contact the family involved, and if it is under the control of the earth priest or chief, then the stranger must contact them. In any case, it is important to notify the chief of any land agreement between an indigene and a stranger farmer. This is done for the chief to serve as a witness to the agreement in case there are future disputes on the land. The chief is notified with an unspecified gift - drinks, money or livestock depending on the strength of the prospective farmer. Family heads, earth priests, chiefs and elders are given some of the farm produce by stranger farmers at the end of the harvest.

In the Karaga District, the land tenure system is of the centralised type where the chief and his sub-chiefs control all lands, even though families have user rights over their inherited family lands called gbansugu. In the Karaga District, both migrants and indigenes must go to the chief directly for farmlands. In some instances, vacant lands can be cultivated by indigenes without the chief's knowledge, but he has the authority to call for those lands if they are needed for developmental purposes. Cola nuts are used to request the land and, once granted, the farmland is controlled but not owned by the person who made the request. The land can be passed on from generation to generation, thus similar to the practice of family lands in the Builsa South communities. A stark difference here is that while in Builsa, the chief's control of land is limited to only the valley and uncultivated bushlands, in Karaga District, the chief controls, allocates, adjudicates and confiscates lands. There is a noticeable absence of earth priests in Karaga, who are re-labelled shrine priests, thus depriving them of any role in land matters.

In the Karaga communities, strangers can access farmlands by going to the community chiefs. A stranger is led to a chief by a native and he/she becomes that native's stranger. The chief then grants access to farmland from the unused reserves, or where the native who brought the stranger has excess lands, is granted permission to share his lands with the stranger. The stranger is expected to pay a token to the chief in the form of Cola nuts, token cash and an annual portion of the harvest. These arrangements are often not supported with documentation, and control of land is established by the cultivation of portions of the land. Very few farmers or companies resort to documentation (none captured by the sample). Uncultivated lands may be reallocated to new strangers.

\subsection{Labour forms and systems}

Labour as an input in agricultural production remains important, regardless of the level of mechanisation or scale of operation. With more capital (i.e. agricultural machinery) and farmland, labour becomes more productive and that is expected to reflect in agricultural output level, and subsequently the scale of operation. All else equal, farmers with small farmlands are more likely to rely on help from other members of their households, mainly because such farmers typically farm at the subsistence level; or may join farmer/labour groups that help members on their respective farms on a rotating basis. Then, as the farmlands increase, farmers may engage the labour services of other farm workers outside their families and groups; or may use relatively more sophisticated machinery that may require fewer labour services if they can afford. In discussing labour use among farmers, we look at the role or contribution from other household members, and then the use of labour beyond the household. This categorisation is adopted based on the massive reliance of farmers on household labour services from our preliminary analysis. In the case of farm workers from households, we present the proportion of farmers who receive labour services from their households. Regarding labour beyond the household, we look at 
the use of hired and voluntary labour. For a farmer to benefit from voluntary labour, (s)he must be a member of a reciprocal/rotating farmer group. Therefore, in Table 6.1, we compare farmers who exploit this option to their counterparts who do not. With hired labour, we further provide where these migrant workers are sourced from. We proceed by presenting the labour used in both the pooled sample, and variation across the six villages/towns to highlight any village-specific characteristic(s). Then, Table 6.2 presents a similar description by looking at the differences (if any) across farm systems and scale of operation.

The statistics from Table 6.1 seem to suggest that members of households automatically provide labour services to farmers. Thus, over 90 per cent of farmers receive labour help from members of their respective households (see row 1). In fact, in Weisi, all farmers receive labour contributions from their respective households.

From Table 6.1, the use of hired labour appears very widespread, with over 70 per cent of farmers indicating use of hired labour in the pooled sample. This observation is also evident even within individual localities (apart from Uwasi). ${ }^{5}$ However, more farmers in Gbedembilisi, Tamalgu and Weisi, use both hired labour (100 per cent, 88.2 per cent and 86.2 per cent, respectively). With the exception of Gbedembilisi, hired labour is mostly comprised of indigenes. Although the use of hired labour in Uwasi was relatively not very extensive, almost all hired labourer (96.4 per cent) are indigenes - likely because over 90 per cent of the farmers interviewed in that village operate on a small- or lower-medium scale. It is also associated with a lag in opening up Uwasi to changes in the social organisation of farming. Gbedembilisi and Weisi are communities that are far advanced in the participation of capitalist farming, which depended mostly on hired labour by stranger farmers compared to Uwasi. Table 6.1 also shows the importance of being a member of a reciprocal/ rotating farm group as, overall, the majority (54.5 per cent) of farmers benefited from such support groups in the pooled sample. Even though the community variations were not very substantial, it is important to note that slightly fewer farmers in Maligunayili and Nyong (42.9 per cent and 43.8 per cent, respectively) took advantage of this support group.

From Table 6.2, household labour services remain useful regardless of the farm system and scale of operation. Even among the large-scale farmers, all farmers interviewed acknowledge labour contribution from their household members. Concerning the use of labour services beyond household members, smallscale and compound farmers subtly stand out, as a

Table 6.1: Labour use by farming communities

\begin{tabular}{|c|c|c|c|c|c|c|c|}
\hline \multirow[b]{2}{*}{ Labour use } & \multirow[b]{2}{*}{$\begin{array}{l}\text { Pooled } \\
\text { sample }\end{array}$} & \multicolumn{6}{|c|}{ By locality } \\
\hline & & Maligunayilit & Tamalgu & Nyong & Gbedembilisi & Weisi & Uwasi \\
\hline \multicolumn{8}{|c|}{ Contribution from household members } \\
\hline Yes & 95.7 & 94.3 & 98.0 & 92.2 & 96.2 & 100.0 & 93.1 \\
\hline \multirow[t]{2}{*}{ No } & 4.4 & 5.7 & 2.0 & 7.8 & 3.9 & 0.0 & 6.9 \\
\hline & \multicolumn{7}{|c|}{ Use of labour beyond household } \\
\hline \multicolumn{8}{|c|}{ Voluntary labour from rotating labour group } \\
\hline Yes & 54.52 & 42.9 & 60.8 & 43.8 & 61.5 & 60.0 & 58.6 \\
\hline No & 45.48 & 57.1 & 39.2 & 56.3 & 38.5 & 40.0 & 41.4 \\
\hline \multicolumn{8}{|l|}{ Hired labour } \\
\hline Yes & 76.92 & 80.0 & 88.2 & 73.4 & 100.0 & 86.2 & 48.3 \\
\hline No & 23.08 & 20.0 & 11.8 & 26.6 & 0.0 & 13.9 & 51.7 \\
\hline \multicolumn{8}{|c|}{ Source of hired labour } \\
\hline Indigenes & 67.0 & 57.1 & 75.6 & 51.1 & 42.3 & 75.0 & 96.4 \\
\hline $\begin{array}{l}\text { Migrants (living } \\
\text { within comm.) }\end{array}$ & 10.4 & 10.7 & 15.6 & 25.5 & 3.9 & 1.8 & - \\
\hline $\begin{array}{l}\text { Migrants (living } \\
\text { outside comm.) }\end{array}$ & 22.6 & 32.1 & 8.9 & 23.4 & 53.9 & 23.2 & 3.6 \\
\hline
\end{tabular}

Note: Figures are percentages.

Source: Authors' own (survey data, 2020)

5 In Uwasi, only about 48 per cent of the farmers used hired labour. 
little over two-thirds of them (67.3 per cent and 67.7 per cent, respectively) either hire or capitalise on voluntary labour. Meanwhile, the engagement of indigenes as hired labour reduces along the scale of operation; and are rather substituted by migrants (mostly from outside the community). As shown in Table 6.2, hired labour for large-scale farmers is mostly comprised of migrants from outside the communities (43 per cent). Among the farm systems, riverine-land farmers predominantly (59.5 per cent) hire labour outside their communities. This is due to time and the need to quickly sow and harvest cowpea to meet moisture conditions before the riverbanks dry up or bushfires destroy farms. During the sowing of cowpea, almost all household labour is fully engaged, thus making it difficult for reciprocal labour arrangements among small farmers to occur. Even small farmers do not have the time to go work on bigger farms for wages, because they simply do not have the labour to spare. This results in the import of labour from other communities to supplement labour shortfalls. This is in tandem with Wahab, Jirström and Hall (2020) who find that labour and tenure dynamics are key socioeconomic correlates of maize yield levels.

Initially, payments for harvesting cowpea were in kind rather than cash, because the riverine system began with small-scale farmers who did not have cash, and therefore established a system of proportional payments to the amount harvested by labour. Given the high value of cowpea, ready markets, and its nutritious value for households of labourers, this became an acceptable arrangement. However, men who harvest cowpea are paid in cash while the women are paid in kind. This is because men do not take part at the processing stage ${ }^{6}$, which defines how much has been harvested. The men mainly pick, while women pick, thresh and winnow to produce the final fine seed. This discrimination is both negative and positive for women, depending on the scale of harvest. On a small scale, it is beneficial as a nutritional source for poor labourers, but on a large scale, the farmers are transferring their risks and expenditures of transport and quality of the beans onto the labourers, thereby affecting women negatively. Due to mechanisation and the large size of farms, farmers changed the harvesting process to include the uprooting of the whole plant and its transport to a central point, before it is threshed with a tractor, and winnowed by women. There is no known processing machine for cowpea yet. Labourers uprooting and gathering a hectare of cowpea receive GHC28, ${ }^{7}$ while women winnowing receive GHC20 per day or an equivalent in grain. Similarly, men and women labourers uprooting soybean in Karaga District receive GHC28 per hectare, and for gathering or conveying to the tractor fitted with a processor is $\mathrm{GHC1} 6$ per harvest from a hectare. The tractor-processor is paid one bag

Table 6.2: Labour use by the scale of operation and farming system

\begin{tabular}{|c|c|c|c|c|c|c|c|c|}
\hline \multirow[b]{2}{*}{ Labour use } & \multicolumn{4}{|c|}{ By the scale of operation } & \multicolumn{4}{|c|}{ By farm system } \\
\hline & Small & $\begin{array}{l}\text { Lower- } \\
\text { medium }\end{array}$ & $\begin{array}{l}\text { Upper- } \\
\text { medium }\end{array}$ & Large & $\begin{array}{l}\text { Compound } \\
\text { farm }\end{array}$ & $\begin{array}{l}\text { River land } \\
\text { farm }\end{array}$ & $\begin{array}{l}\text { Upland } \\
\text { farm }\end{array}$ & $\begin{array}{l}\text { Valley } \\
\text { farm }\end{array}$ \\
\hline \multicolumn{9}{|c|}{ Contribution from household members } \\
\hline Yes & 96.2 & 95.1 & 85.7 & 100.0 & 95.4 & 97.8 & 95.1 & 96.2 \\
\hline No & 3.9 & 4.1 & 14.3 & 0.0 & 4.6 & 2.2 & 4.9 & 3.9 \\
\hline \multicolumn{9}{|c|}{ Use of labour beyond household } \\
\hline $\begin{array}{l}\text { Hired or } \\
\text { voluntary }\end{array}$ & 67.3 & 50.0 & 57.1 & 42.9 & 67.7 & 53.3 & 58.9 & 50.0 \\
\hline $\begin{array}{l}\text { Both hired and } \\
\text { voluntary }\end{array}$ & 32.7 & 50.0 & 42.9 & 57.1 & 32.3 & 46.7 & 41.1 & 50.0 \\
\hline \multicolumn{9}{|c|}{ Source of hired labour } \\
\hline Indigenes & 70.9 & 66.0 & 57.1 & 42.9 & 90.0 & 38.1 & 67.5 & 77.3 \\
\hline $\begin{array}{l}\text { Migrants (living } \\
\text { within comm.) }\end{array}$ & 9.9 & 10.4 & 14.3 & 14.3 & - & 2.4 & 15.9 & 13.6 \\
\hline $\begin{array}{l}\text { Migrants (living } \\
\text { outside comm.) }\end{array}$ & 19.4 & 23.6 & 28.6 & 42.9 & 10.0 & 59.5 & 16.7 & 9.1 \\
\hline
\end{tabular}

Note: Figures are percentages.

Source: Authors' own (survey data, 2020)

$6 \quad$ Men do not take in threshing and winnowing, mainly because these are perceived as primarily female activities.

7 This is equivalent to about US\$10.56. As of August 2020, when the survey was conducted, US\$1 was equivalent to GHC5.68. 
for processing ten bags for the farmer. For groundnuts and peanuts, men uproot groundnuts using group labour, so they do not pay each other. However, with larger farms, labourers are paid GHC24 per hectare. Then, women collect and pluck the peanuts with their remuneration being in kind: for every five bags or equal heaps, the labourer gets one bag or heap. Other farmers offer one bag for every four bags plugged when competition for labour is high. For maize harvesting in Karaga District, it is mainly migrants from the Upper East Region who come during harvest. They break corn ears from 0.8ha for a remuneration of one bag of shelled maize. They are provided accommodation, food and water for free.

The qualitative data identify several forms of labour that farmers use to achieve their intended goals. The first is own or household labour, which is provided by the framer and his/her household. Household labour can be relied on especially when there are more workingage members within the family. In Builsa, this form of labour is on the decline, as most households' children attend to school and are not always available to provide the labour needs on the farms. Another form of labour used by small farmers is communal labour, though this form of labour is nearly extinct as most farmers are no longer interested. Reasons given for this include the lack of reciprocity demonstrated by some farmers when it is their turn to help farmers who have worked for them, and the introduction of agrochemicals which is cheaper if compared to the cost of feeding communal group members. Associated with this form of labour is group labour, in which farmers organise themselves into groups of about six who work on each other's farms on a rotational basis.

Own labour is often combined with hired labour by most farmers. The activities that attract hired labour are sowing, weed control and fertiliser application. Hired labourers are expected to be fed during work, and payment is instant at the end of a day's work. Hired labour started around the 1970s, as observed by an interviewee: "I started using hired labour in 1978. During those times, several items were used to hire labourers. It could be a shirt, trousers, money or grains. People come to ask for these items from you and will, in turn, bring labourers to help on your farm" (male farmer Weisi, August 2020). There is an increasing trend in the availability of hired labour, as more small farmers are willing to offer their spare time for cash on the farms of medium- and large-scale farmers, supported as in: "At the time I started farming, there was no by-day and we relied on household labour. Now, however, I rely mostly on by-day labour and they are available" (excerpt, male farmer Weisi, August 2020). The rise in hired labour is associated with the activities of commercial rice farmers, which confirms the observation by Hear (1984) that the increasing use of hired labour in rural areas is associated with the emergence of commercial rice production.

Contract labour is not common in Builsa compared to Karaga, but there are instances in which some farmers use this kind of labour such as during cowpea harvesting. This is supported by an interviewee who stated that: "During cowpea harvest, the labourers who come from outside the community can go into a contract with me instead of the by-day arrangement. In this contract, I agree with the labourer on the amount to be paid when cowpea on the farm is harvested and processed. The accommodation and feeding of the labourer is borne by me" (excerpt, 36-year male farmer, Weisi, August 2020).

There is a mixed reaction to gender differentiation in hired labour work by both male and female hired labourers. While some of the farmers interviewed stated that there are gender differences in hired labour, work with male farmworkers performing more difficult tasks than their female counterparts, others stated that there exists no such difference. In addition, some farmers observed that male and female hired farmworkers are given different wages, while others seem to see no differences in wages between them. These observations notwithstanding, there is an increase in the availability of hired labourers over time in the two areas.

\subsection{Technology use among farmers}

The adoption of technology is important in contributing to the emergence of medium-scale farms in the study area, as it is linked with farm size expansion and increases in farm yields. Four main technology adoptions - i.e. use of tractors, herbicides/weedicides, improved seeds, and fertilisers - are considered (based on the process of land preparation through to harvesting). Therefore, in Table 6.3, we present the percentage distribution of farmers with regard to the use of these technologies. Columns 2 to 5 consider the use of any one of the four technologies. Then in column 6 , we present the percentage distribution of farmers that use at least one of the four. The final column shows the percentage distribution of farmers who use all four technologies. As in the earlier sections, the discussions are carried out from two perspectives. First, we focus on the pooled sample and locality-specific variations (if any) in the use of technology (presented in Table 6.3). Then in Table 6.4, we present a similar discussion about technology use by farm-scale and systems.

There appears to be wide use of at least one mode of the four technologies (tractors, herbicides, improved 
seeds and fertiliser). Specifically, about 56.9 per cent of the farmers interviewed use at least one mode of these technologies. Furthermore, about four in every ten farmers use all four technologies (column 7). The use of herbicides/weedicides and tractors are the most common technologies used by farmers (96 per cent and 93 per cent of farmers, respectively), while improved/hybrid seeds are used by barely half of the farmers - hence being the least common technology used. Some farmers are of the view that seed growers are not honest, often leading to lower rates of germination and low yields if these improved seeds are purchased from seed growers. In Builsa, for instance, some farmers observed that they had been victims of grain sold to them as improved seeds. This affected crop germination and yield.

In terms of locality-specific use of technology, as shown in Table 6.3, the use of technology is more common among farmers in Gbedembilisi and Weisi; such that an overwhelming majority (88.5 per cent and 78.5 per cent, respectively) use improved seeds, which is relatively less common in areas such as Maligunayili (22.9 per cent) and Tamalgu (25.5 per cent). Qualitative data corroborate the increasing use of certified seeds among farmers in Gbedembilisi and Weisi, but show variations among the different categories of farmers. Besides, in these two localities (Gbedembilisi and Weisi), as in other regions (Wahab, 2020), the use of herbicides is widespread.

The use of technology (with the exception of improved seeds) remains impressive across farm-scale and systems, as over half of farmers in respective groups use the selected technologies. In particular, the use of herbicides and fertiliser is universal among uppermedium and large-scale farmers. However, in terms of technology application along the entire process of

Table 6.3: Technology use by farming communities

\begin{tabular}{|l|l|l|l|l|l|l|l|}
\hline & Tractors only & $\begin{array}{l}\text { Herbicides } \\
\text { only }\end{array}$ & $\begin{array}{l}\text { Improved } \\
\text { seeds only }\end{array}$ & $\begin{array}{l}\text { Fertiliser } \\
\text { only }\end{array}$ & $\begin{array}{l}\text { At least one } \\
\text { technology }\end{array}$ & $\begin{array}{l}\text { All four } \\
\text { technologies }\end{array}$ \\
\hline Pooled sample & 93.3 & 95.7 & 48.8 & 81.9 & 99.7 & 43.1 \\
\hline By locality & 97.1 & 100.0 & 22.9 & 80.0 & 100.0 & 22.9 \\
\hline Maligunayili & 92.2 & 98.0 & 25.5 & 80.4 & 100.0 & 17.7 \\
\hline Tamalgu & 95.3 & 82.8 & 43.8 & 73.4 & 98.4 & 37.5 \\
\hline Nyong & 96.2 & 100.0 & 88.5 & 96.2 & 100.0 & 80.8 \\
\hline Gbedembilisi & 98.5 & 100.0 & 78.5 & 98.5 & 100.0 & 75.4 \\
\hline Weisi & 82.8 & 98.3 & 39.7 & 69.0 & 100.0 & 31.0 \\
\hline Uwasi & & & & & \\
\hline
\end{tabular}

Note: Figures are in percentages.

Source: Authors' own (survey data, 2020)

Table 6.4: Technology use by farming systems and farm scale

\begin{tabular}{|c|c|c|c|c|c|c|}
\hline Technology use & Tractors only & $\begin{array}{l}\text { Herbicides } \\
\text { only }\end{array}$ & $\begin{array}{l}\text { Improved } \\
\text { seeds only }\end{array}$ & $\begin{array}{l}\text { Fertiliser } \\
\text { only }\end{array}$ & $\begin{array}{l}\text { At least one } \\
\text { technology }\end{array}$ & $\begin{array}{l}\text { All four } \\
\text { technologies }\end{array}$ \\
\hline \multicolumn{7}{|c|}{ By scale of operation } \\
\hline Small & 91.0 & 93.0 & 28.9 & 71.2 & 99.4 & 21.2 \\
\hline Lower-medium & 95.9 & 98.4 & 67.2 & 92.6 & 100.0 & 63.9 \\
\hline Upper-medium & 92.9 & 100.0 & 85.7 & 100.0 & 100.0 & 78.6 \\
\hline Large & 100.0 & 100.0 & 100.0 & 100.0 & 100.0 & 100.0 \\
\hline \multicolumn{7}{|l|}{ By farm system } \\
\hline Compound farm & 86.2 & 93.9 & 30.8 & 61.5 & 98.5 & 23.1 \\
\hline River land farm & 97.8 & 100.0 & 82.2 & 97.8 & 100.0 & 77.8 \\
\hline Upland farm & 94.5 & 94.5 & 42.9 & 85.3 & 100.0 & 37.4 \\
\hline Valley farm & 96.2 & 100.0 & 73.1 & 84.6 & 100.0 & 69.2 \\
\hline
\end{tabular}

Note: Figures are in percentages.

Source: Authors' own (survey data, 2020) 
farming (i.e. land preparation to harvesting), from Table 6.4 , only about one in every five small-scale farmers uses all four technologies. This significantly jumps to about three in every five farmers among lowermedium scale farmers. Then, among upper-mediumscale farmers, about eight in every ten farmers use all four technologies. Overall, medium- and large-scale farmers use more certified seeds compared to smallscale farmers. This is supported by the excerpt, "small farmers sow grain while medium and large farmers sow certified seeds" (excerpt, extension officer, Fumbisi August 2020). Meanwhile, all large-scale farmers interviewed use the four technologies (see column 7). The increase in the use of all four technologies along the scale of operation may partly be attributed to the availability of funds, as farmers who operate on a bigger scale are more likely to be wealthier. They are also typically more educated and have access to extension officers and input dealers at district and regional levels.

In terms of farm systems, the use of technology is very common among valley-land farmers compared to the other systems. This can be explained by the presence of large-scale rice farmers, who are mostly strangers but have encouraged locals to also venture into large-scale rice farming. Large-scale farmers are noted through interviews to own and use more technologies than small-scale farmers, as supported by an interviewee who explains that: "Large farmers use more technology. With the small farmers, technology use is insignificant as they have no access to these kinds of technologies." (Excerpt, Director, District Department of Agriculture, Fumbisi, August 2020). This is supported by another interviewee: "large commercial farmers use more technology than smaller farmers. Small farmers enjoy the technology brought by large farmers, as they often rely on them for farm machinery such as tractors, shellers and combine harvesters" (excerpt, extension officer Fumbisi, August 2020). It is additionally explained by the presence of commercial cowpea cultivation, which relies on the intensive use of pesticides and insecticides. Nonetheless, there is high use of any of these technologies (except improved seeds) among all farmers. This can be explained by mistrust and deception from some certified seed growers and input dealers over the years. Qualitative interviews suggest that some certified seeds performed poorly at the germination and yield stages compared to farmer-saved seeds. An interviewee notes that: "smallholders did not also have confidence in the marketed seeds. They feel that good seeds come from only the Ministry of Food and Agriculture. They do not have confidence in seeds sold by input dealers retailed in the market. So, they trust their seeds more than the certified seeds marketed by input dealers" (excerpt, Director, District Department of Agriculture, Fumbisi,
August 2020). The use of herbicides and weedicides is universal among river-land and valley farmers, and an appreciable majority (82.2 per cent and 73.1 per cent, respectively) of these farmers also use improved/hybrid seeds. Meanwhile, only about 31 per cent and 43 per cent of compound and upland farmers, respectively, use improved seeds. The study establishes that, contrary to the official narratives and the postulations of the extant literature on the usage of farm inputs and technology by small and larger farmers, there is no marked difference in technology adoption among farmers except for improved seeds. The poor usage of improved seeds among smaller farmers is the result of the seed production and retail systems' failure rather than the refusal by these farmers to use them.

In terms of gender, women are observed to adopt technology faster and easier than their male counterparts as noted by an officer: "Women accept to learn and endure more than men when it comes to innovations. When a demonstration field is set for a male and female farmer, females learn faster than the males" (excerpt, extension officer, Fumbisi, August 2020). Women are noted to be good listeners and are eager to learn, compared to their male counterparts who often view some new procedures by extension officers as a waste of time. At the community level, it is noted that communities that are farther away from the district capital adopt more technology than those closer. Rich farmers are also noted to use more technology than poor farmers, as noted by some of the interviewees.

\subsection{Financing farm operations}

This section discusses the sources of finance for farming activities, as well as avenues that farmers use for marketing their farm produce in the study districts. Sources of finance in agriculture are of utmost importance, because it not only determines the scale at which one engages in the farming enterprise, but also the ability to accumulate and marshal capital is essential to increasing one's scale of operation. Our results shows that finance is the main determinant as to whether one is a small-, medium-, or large-scale farmer. Farmers in the study communities rely on a variety of sources to finance their farming activities. In this report, we categorise these sources into farm, offfarm, and non-farm sources.

The sale of farm produce, particularly grains and livestock, is the primary source of finance for a vast majority of farmers in both study districts. This source of finance is becoming even more significant, as farmers continuously increase their scale of production beyond the subsistence level. As a source of finance, there is often the tendency to sell a crop 
with a relatively lower commercial value and invest the proceeds into the production of a crop that has a relatively higher commercial value. For example, some of the relatively upwardly mobile farmers report selling vegetables to finance their maize farms, while others report selling their maize produce to finance their rice farms. While the first point of call is the sale of farm produce to finance farm activities, the sale of livestock is also common, especially in the Builsa area, when challenges need to be addressed in the course of the season. For example, when the Fall Army Worm infestation became widespread on maize fields, some farmers had to fall on the sale of livestock - including those bequeathed to them by their predecessors - to purchase insecticides for their farms.

Apart from the sale of farm produce and livestock, farmers in the study districts also rely on off-farm sources of income to finance their farm activities. These include (i) incomes from renting out tractors and other farm machinery, (ii) selling one's labour on larger farms, and (iii) trading in farm produce. Income from the renting out of tractors is most important in the Karaga District, where larger farmers who have had to reduce their scale of production find that they need to release their tractors to plough other farmers' fields to break even, given the high cost associated with tractor maintenance. Payment for such services could be either in cash or produce. In the case of the latter, there must be trust between the tractor owner and small farmer, so that the former does not fear that the latter would claim inability to pay due to crop failure. Some small farmers assert that the way to build this trust is to invite the tractor owner to inspect the failed crops at harvest time. Income - both from cash and sale of produce - often helps in financing tractor owners' farm activities. The sale of one's labour on large farms is another important source of off-farm income to finance farm activities. This activity is engaged in by both males and females. In Builsa, this is most common in the rice valleys, as well as the large cowpea fields. Thus, despite the increased mechanisation witnessed in the study communities, the hiring of labour for such activities as removal of tree stumps, sowing/planting/broadcasting, weed control, fertiliser application and harvesting, among others, is critical, and is required by farmers at all scales of operation where family labour does not suffice. The use of hired labour is most pronounced in some communities - Gbedembilisi in the Builsa District and Nyong in the Karaga District - but virtually nonexistent in Uwasi, because these are the hotspots for commercial farmers, especially migrants who do not have family labour and also cultivate large acreages. Some crops, such as cowpea and soya beans, require more man-hours than others. Incomes from

Figure 6.1: Sources of finance by the scale of production

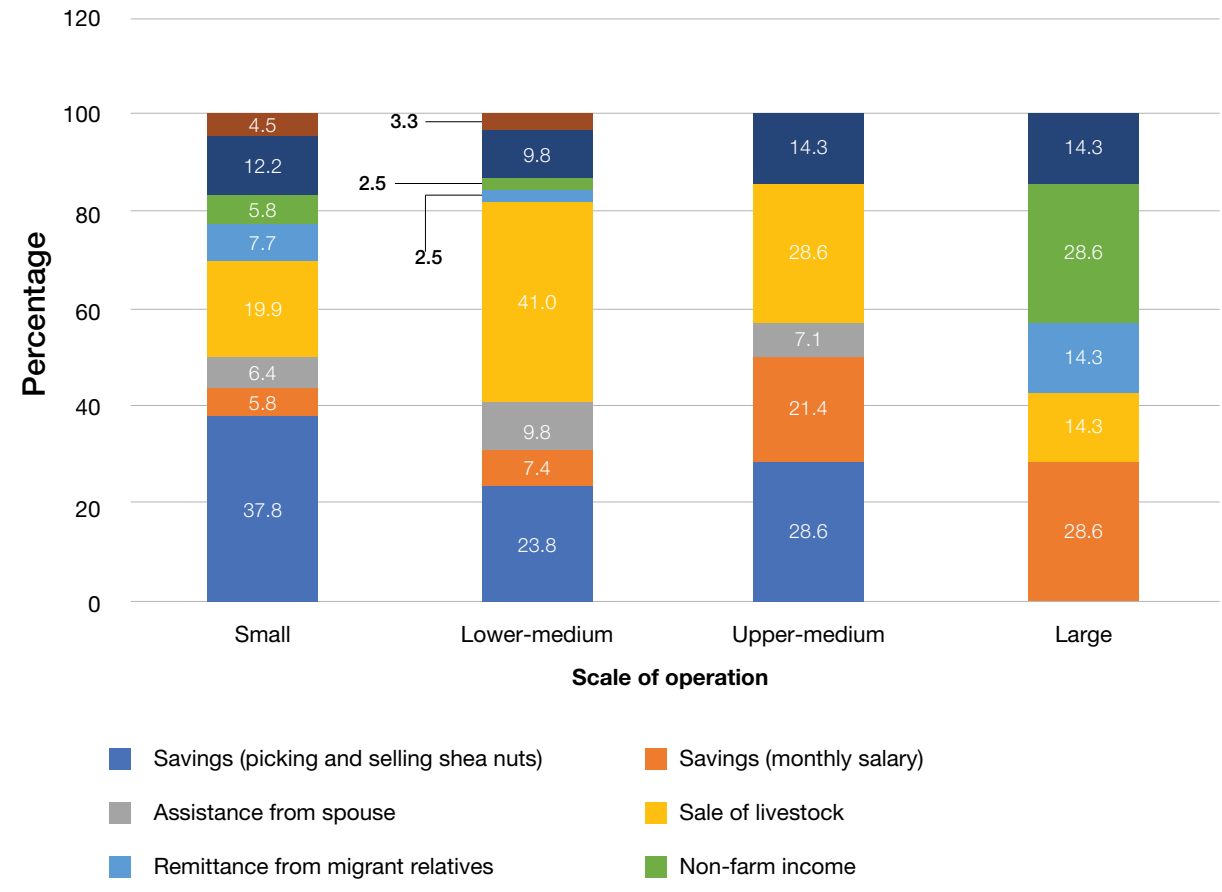

Source: Authors' own (survey data, August 2020) 
selling one's labour on larger farms, especially with the proliferation of stranger farmers who tend to offer better terms of payment than their local counterparts, is thus an important source of finance. The third offfarm income source is the trading in farm produce. This includes not only buying and selling groundnuts, maize, millet and sorghum, but also picking and processing shea nuts. These activities are mainly engaged in by women. Other women also cook and sell farm produce as food to finance their farm activities.

The third source of finance for farm activities is non-farm sources, such as savings from non-farm employment, remittances from family members, and loans from community members, banks and NGOs.

As shown in Figure 6.1, own savings is the most important source of finance for all scales of production. The point of departure, however, is that while savings for small farmers are mainly from off-farm activities such as picking and selling shea nuts, sale of labour on other farms, and savings from the sale of farm produces, finance for large farmers is mostly from nonfarm sources, such as savings from monthly incomes, proceeds from other non-farm businesses, and remittances from migrant relatives. Also noteworthy is the critical role that the sale of livestock plays in the financing of farm activities for small, lower-medium, and upper-medium farmers. The narrative is the same when the sources of finance are ranked against farming systems. The sale of livestock plays the most important role in farm finance in compound farming systems, followed by river land systems, upland farms, and valley farms, respectively (Figure 6.2). The other two most important sources of finance are incomes from off-farm activities for uplands, river lands and compound farming systems, while monthly incomes are most important for valley farming systems where urban-based farmers prefer rice farming.

Banks and NGOs also play important role regarding agriculture financing in Ghana, and the study areas are no exception. Owing to the inherent uncertainty that is characteristic of farming in these parts of the country, not only do farmers tend to be averse to taking loans to finance their farm activities, but these financial institutions also tend to be apprehensive in giving out such support. Nonetheless, about 26.1 per cent of the farmers revealed they had previously received some form of financial assistance or a loan from a financial institution. Meanwhile, the few NGOs who assume the risk of financing farming often charge high interest rates to compensate for those risks. A 48-year-old lower-medium female farmer narrates how she paid $\mathrm{GHC} 220$ on top of a $\mathrm{GHC} 1,000$ loan within four months. It is gratifying to note that some of

Figure 6.2: Sources of finance by farming systems

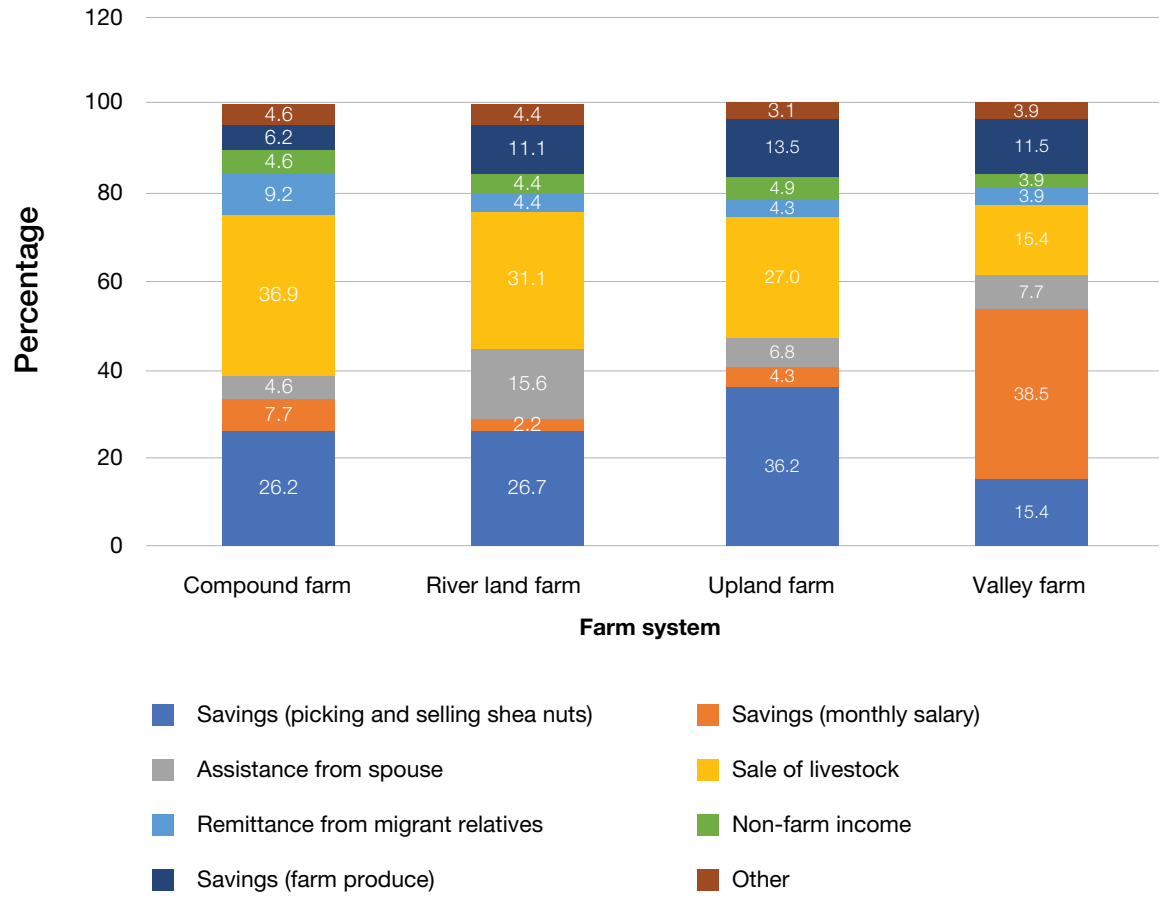

Source: Authors' own (survey data, August 2020) 
these organisations are making efforts to improve their services to farmers. For example, while Vision Farms extends the payback duration to six months, E for Life offers technical as well as financial support to farmers. Despite the efforts of such institutions, the activities of others do not support farmers. One farmer in a FGD in Nyong narrates how they were duped by an NGO under the guise of supporting them: "an organisation came and took our money in the name of helping us cultivate sorghum. They took GHC133 each from us, making a total of $\mathrm{GHC} 17,800$...they said it was meant for our registration." 


\section{DISCUSSION AND CONCLUSIONS}

The historical development of commercial agriculture in northern Ghana is important in order to locate the current context of the rise of medium-scale farms. The consistent efforts by the state and NGOs in the postindependence era is critical in propelling the growth of farms through subsidised inputs, dissemination of innovations, mechanisation and land development. The rise of medium-scale farms in contemporary times is not merely the result of the conflation of factors often cited by the literature, but this phenomenon has historical antecedents underlain by cogent political economy forces. Efforts at modernising northern agriculture dates back to immediate post-independence actions by the Nkrumah and the Acheampong governments. The development of state farms, cooperative farms, and individual commercial farms with massive state support in mechanisation and green revolution technologies are notable in building the architecture for today's growth in farm sizes (Miracle and Seidman, 1968; Bennett and Schark, 1979; Konings, 1984). The opening up of income-earning opportunities has seen the influx of urban-based investors into rural agriculture since the late 1960s in northern Ghana, with waves reflecting opportunities opened by the state and NGOs. The role of the state is, therefore, critical in agricultural commercialisation and the growth of farms in rural Africa. This is partly because the private sector is limited, and actors need infrastructural and innovation support to thrive. This is not peculiar to Africa, as all developed countries and emerging economies made significant investments for their private sectors to pick up. Illustrating the role of the state was the death of many medium and large farms in the 1980s, when Ghana introduced the Structural Adjustment Programme which prescribed the withdrawal of most support for food production (Yaro, 2013; Amanor, 2017). The growth of the private sector from the 1990s as a conscious effort by government, and also as a response to fill voids created by state withdrawal, has seen a new dynamic space in agrarian development in Ghana with increased modern input availability and mechanised services (Ngeleza et al., 2011; Kansanga et al., 2019a).

Contrary to assertions by Benin (2015) and Daum and Birner (2017) that state interventions create distortions of agricultural policy in contravention of neoliberal market ideals, we argue that these policies were useful to the extent that they promoted technological uptake, which helps in bringing more land under cultivation and facilitates private sector participation in input supply. The Ghanaian state, as noted in Amanor and Iddrisu (2021) and Amanor (2019), has been responsible, through policies aimed at subsidising agriculture, for creating social differentiation in rural communities through the appropriation of state largesse by the elite, businesspeople, politicians and local chiefs and their associates. We, therefore, see the upper-medium farmers and large farmers having a history that fits with their abilities to capture these state support systems and appropriate processes spawned by the state to their advantage, as captured in previous studies (Konings, 1986; Yaro, 2013; Amanor, 2017). These include the capture of tractors, inputs, finance, markets and land. Thus, drivers of farmland increases often alluded to are merely a consequence of state action and inaction, and the resultant processes these create.

The state of agricultural commercialisation in Ghana, characterised by high cost of production, declining soil fertility and availability of vast lands in some hitherto inaccessible areas, has created opportunities for farmers with more resources. Though many small farmers have succeeded in taking advantage of the growing opportunities in food production by upscaling their farms, they still suffer from multiple challenges, including access to land, labour, inputs, and mechanisation services. The growth of medium-scale farming is higher among the lower-medium group, because these are farmers who are stepping up from subsistence production to meet increasing market demand. The significant growth of the upper-mediumscale farmers, who are composed of urban-based and wealthy rural farmers, is important as they possess the technological keys to modernising agriculture (Kansanga 2017), and act as a catalyst for growth among lower-medium farms, as noted also by several studies across Africa (Liverpool-Tasie et al., 2020).

The impressive growth in farm sizes comes with new challenges in terms of changing land tenure relations, labour scarcities, expensive innovations, limitations of markets or functioning value chains, and limited credit or finance. Different farm scales exhibit different 
characteristics in terms of usage of the factors of production. The abundance of land in so-called 'overseas' areas has provided the opportunity for farmland expansion, particular for migrant and urbanbased farmers. As the demand for land increases and scarcities emerge, especially for lands accessible to the community, the rules and social norms guiding access to land change (Gyapong, 2021; Totin et al., 2021). These processes are similar to those of commodification of land in peri-urban northern Ghana, where reinterpretations of traditions are being made to allow allodial title holders, such as chiefs and earth priests, to allocate land for financial and other gains. Women farmers who have always had a poorer access to land continue to suffer from traditional impediments except for richer women who defy the gender discrimination. It does seem that changes in tenure relations hardly work to the advantage of women because of the commoditised ethos of the time. The ability of small and lower-medium farmers to accumulate more land now depends on deploying financial, social and mobility resources which are limited in varying proportions. Upper medium farmers and large farmers therefore have an upper hand compared to the others because they are preferred by both the state and the traditional authorities.

Inequalities in land access reflect social differentiation emerging from the commercialisation of the agrarian system. Land inequality is extremely high in the valley farms for rice because of large-scale farmers, where only two farmers growing 404.7ha each will equate to over 100 households on the lower-medium-farm scale. Inequalities in access to land are lowest on compound farms, but higher on riverine, upland and valley lands. Female participation in the increasing farm sizes is impressive, but still lags that of men. Female farmers' major problems in expanding farms still revolve around power asymmetry, mobility challenges, poor access to technical support and dependence on men to access lands. Land relations are changing rapidly, together with social relations in these communities, as land constitutes the fulcrum around which all other relations revolve. The emerging land conflicts in these communities are largely a result of the leasing of land to strangers, which is creating an increasing scarcity of lands closer to the communities. Hitherto, such lands were accessible to smaller, lower-medium-scale and female farmers. Amanor and Iddrisu (2021) allude to the fact that larger farmers appropriate lands from chiefs for whom they provide tractor services and other financial inducements. The implication of the shifting farming frontiers for female farmers is that they are unable to travel far to cultivate bushlands, even in the increasingly accessible northern landscape made possible by cheap Chinese motorbikes and tricycles. Farmland expansion is thus becoming a privilege for richer farmers and the custodians of the land, to the relative disadvantage of stepping-up farmers whose limits will soon be reached.

The growth of farmlands is associated with rising labour challenges, which result in changing labour relations due to the commodification of labour in the context of labour scarcities and substitution by mechanisation. The household heads' control over family labour is waning, as individuals independently cultivate farms and also sell off their labour. The traditional allocation of tasks and obedience to the family head, whose responsibility was to supply all needs of household members, is changing rapidly as people negotiate new relations. Amanor and Iddrisu (2021) aptly note that there is a decline of the patriarchal, lineage-based, compound farm, and the emergence of individual farms cultivated by younger males and females, tied to a process of increasing social differentiation. This summarises the processes uncovered by our study, of dwindling household head control over family labour depending on the individual's degree of freedom. The degree of freedom obtained in turn can be dependent on the size of individual farms and, therefore, the financial locus of that individual which defines his/her relationship with the head of household. The ability to sell labour to wealthier farmers in exchange for finance, inputs and mechanisation services has also defined new sets of relations between farmers, which are mutually beneficial but also breed a landscape of exploitation among the different farm scales. Though labour requirements have dropped significantly due to innovations in mechanisation, weed control and harvesting technologies, there are still avenues for employment of temporary labour for applying these innovations, and for tasks that still require human interventions.

Our findings underscore the critical point that agricultural modernisation and commercialisation are not constrained by farm scale. The use of factors of production by all farm scales is impressive, with the exception of improved seeds. The divisibility in the use of mechanisation services has been remarkable. The importance of upper-medium farmers who have access to these machines, and the mutual benefits of sharing with small- and lower-medium-scale farmers to reach optimality and recoup their investments is notable. There is a need to examine the difficult problem of improved seed adoption among smaller farmers, which we argue is due mainly to the technical and social structures surrounding the production and propagation of these seeds. The question of trust in the process of mass-produced improved seeds by 
several seed growers, rather than a few companies who can be held responsible for poor seeds, is at the heart of the debate.

The source of finance for farming is varied among the different farm sizes, as smaller farmers depend on livestock, wages from labouring on bigger farms, and sale of farm produce, while bigger farmers have access to loans, salaries from other jobs, and reinvestments from farming. The interdependence of the different farm scales on each other for investment capital, through wages and deferred payment for services such as tractor ploughing and non-cash payments for harvesting and processing, is an important feature engendering the co-dependence and survival of the social relations. These relations of production have characterised previous agrarian systems in Ghana, and also in other countries (Van Der Westhuizen, Jayne and Meyer, 2017; Amanor and Iddrisu, 2021). Depending on the power relations, these arrangements can be mutually beneficial to both groups. As found in numerous other studies, access to formal credit is very limited for smaller farmers (Dzanku, 2019; LiverpoolTasie et al., 2020) compared to urban-based farmers with contacts, collateral, negotiation abilities and political connections.

In conclusion, social differentiation exemplified in marked inequalities in access to land, inputs and extension services, characterises the processes of agricultural commercialisation in the study communities. There is no level playing field for all farmers, as richer and generally male farmers control the resources and determine many aspects of agrarian changes. Smaller farmers with no power in village political structures, and with fewer connections to the political apparatus that doles out state subsidies, have lesser chances of benefitting from the process compared to bigger farmers with influence. Our findings point to tractor ownership, input accessibility, finance and lucrative markets as preserves of the bigger farmers. At every scale of production, there are specific advantages to be drawn, and these define the social inequalities prevalent in the supposedly neutral agrarian landscape, with government policy and NGO activities aimed at modernising small-scale farmers. These processes are, therefore, reborn mechanisms of elite capture which are already well-chronicled in the literature.

Impressive, though not adequate, is the forcefulness of women in commercial agriculture, as shown by the number of women scaling up production and breaking from patriarchal relations to independently engage in commercial production. Though the north has a history of women being symbolically given groundnut farms whose produce are largely destined for the market, the development of these into individual farm businesses is laudable. The commodification of land and labour, and the need to survive in the current neoliberal cash economy of multiple expenses, largely explains the willingness of men to allow their wives to engage in commercial farming. At the same time, the ability to pay for labour and land freely, based on demand and supply, has liberated the northern woman to some extent. However, they are still held down by low financial abilities which reflect past disadvantages. The prospects of women in commercial agriculture are bright, but contingent on the amount of financial and technical assistance from the state and NGOs.

The rise in farmland sizes in northern Ghana has been a phenomenal revolution characterised by an invasion by urban-based investors, usurpation of vast lands by local elites, and the gradual expansion by smaller farmers of their farm sizes over the past two decades. Inclusivity is, therefore, a matter of scale of accumulation of land and access to external resources. The upper-medium and larger farmers appropriate the most resources, but have also been useful in propelling growth among smaller farmers. There is a complex marriage between bigger and smaller farmers, as they complement each other even while larger farmers create problems for their smaller, weaker counterparts.

To create equitable and inclusive commercialised agrarian change, there is a need to address the problems of land inequity and access rules, innovation diffusion, cost of inputs, and functioning value chains and agricultural markets. A community-led approach to defining mechanisms for accessing land in the current competitive landscape is important to prevent further chaotic land relations. It is critical to examine the difficult problem of improved seed adoption among the small- and lower-medium-scale farmers, which, we argue, is due mainly to the technical and social structure of the seeds' production and propagation. The importance of the state, development partners and private sector actors in today's commercial agriculture is non-negotiable. Studies that stress the role of the private sector to the neglect of the role of the state and NGOs miss the point in explaining agrarian change in developing countries. These actors need to invest in innovation to produce appropriate home-grown mechanisation and agro-processing equipment with the accompanying development of human capacities. Also, the current rigidity in marketing needs to be dealt with using both traditionally developed marketing channels and modern value-chains that are efficiently governed. 
Amanor, K.S. (2017) 'Globalization, Agribusiness and the Liberalization of Agricultural Services in Ghana', in: A.M. Buainain, M.R. d. Souza and Z. Navarro (eds.), Globalization and Agriculture: Redefining Unequal Development. Lanham, MD: Lexington Books.

Amanor, K.S. (2019) Mechanised Agriculture and Medium-Scale Farmers in Northern Ghana: a Success of Market Liberalism or a Product of a Longer History? APRA Working Paper 23. Brighton: Future Agricultures Consortium. Available at: https://opendocs.ids.ac.uk/opendocs/handle/20.500.12413/14433 (Accessed: 7 July 2021).

Amanor, K.S. and Iddrisu, A. (2021) 'Old tractors, new policies and induced technological transformation: agricultural mechanisation, class formation, and market liberalisation in Ghana', The Journal of Peasant Studies, 1-21. doi:10.1080/03066150.2020.1867539.

Antwi-Agyei, P., Dougill, A.J. and Stringer, L.C. (2015) 'Impacts of land tenure arrangements on the adaptive capacity of marginalized groups: The case of Ghana's Ejura Sekyedumase and Bongo districts', Land Use Policy 49: 203-212. doi:10.1016/j.landusepol.2015.08.007.

Awen-Naam, M.B. (2019) Local Farming Systems and Food Security in the Builsa Area of Northern Ghana. Doctoral Dissertation. University Of Ghana, Accra. Available at: http://ugspace.ug.edu.gh/handle/123456789/35928 (Accessed: 3 June 2021).

Benin, S. (2015) 'Impact of Ghana's agricultural mechanization services center program', Agricultural Economics 46(S1): 103-117.

Bennett, A. and Schork, W. (1979) Studies toward a sustainable agriculture in Northern Ghana. Heidelberg: Research Centre for international Agrarian Development.

Boone, C. (2014) Property and political order in Africa: Land rights and the structure of politics. Cambridge: Cambridge University Press.

Byerlee, D. and Deininger, K. (2012) 'The Rise of Large Farms in Land-Abundant Countries: Do They Have a Future?', World Development 40(4): 701-714.

Chapoto, A., Mabiso, A. and Bonsu, A. (2013) Agricultural commercialization, land expansion, and homegrown large-scale farmers: Insights from Ghana (Vol. 1286). Washington DC: International Food Policy Research Institute.

Colin, J.-P. and Woodhouse, P. (2010) 'Interpreting land markets in Africa', Africa 80(1): 1-13.

Daum, T. and Birner, R. (2017) 'The neglected governance challenges of agricultural mechanisation in Africainsights from Ghana', Food Security 9(5): 959-979. doi:10.1007/s12571-017-0716-9.

Dickson, K.B. (1968) 'Background to the problem of economic development in Northern Ghana', Annals of the Association of American Geographers 58: 686-696.

Dzanku, M.F. (2019) 'Food security in rural sub-Saharan Africa: Exploring the nexus between gender, geography and off-farm employment', World Development 113: 26-43. doi:https://doi.org/10.1016/j.worlddev.2018.08.017.

Edelman, M., Oya, C. and Borras Jr, S.M. (2016) Global land grabs: History, theory and method. London: Routledge.

Gyapong, A.Y. (2021) 'Commodification of family lands and the changing dynamics of access in Ghana', Third World Quarterly 1-19. 
Hear, N.V. (1984) 'By-day' boys and dariga Men: casual labour versus Agrarian capital in Northern Ghana', Review of African Political Economy 11(31): 44-56. doi:10.1080/03056248408703599.

Houssou, N. and Chapoto, A. (2014) The changing landscape of agriculture in Ghana: Drivers of farm mechanization and its impacts on cropland expansion and intensification. Accra: International Food Policy Research Institute.

Hunter, J.M. (1967) 'Seasonal hunger in a part of the West African Savanna: a survey of bodyweights in Nangodi, north-east Ghana', Transactions of the Institute of British Geographers 167-185.

Jayne, T.S., Muyanga, M., Wineman, A., Ghebru, H., Stevens, C., Stickler, M., Chapoto, A., Anseeuw, W., Van Der Westhuizen, D. and Nyange, D. (2019) 'Are medium-scale farms driving agricultural transformation in sub-Saharan Africa?', Agricultural Economics 50: 75-95.

Jayne, T.S., Chamberlin, J., Traub, L., Sitko, N., Muyanga, M., Yeboah, F.K., Anseeuw, W., Chapoto, A., Wineman, A. and Nkonde, C. (2016) 'Africa's changing farm size distribution patterns: the rise of medium-scale farms', Agricultural Economics 47: 197-214.

Jayne, T.S., Chapoto, A., Sitko, N., Nkonde, C., Muyanga, M. and Chamberlin, J. (2014) 'Is the scramble for land in Africa foreclosing a smallholder agricultural expansion strategy?', Journal of International Affairs 67(2): 35-53.

Jayne, T.S., Chamberlin, J. and Headey, D.D. (2014) 'Land pressures, the evolution of farming systems, and development strategies in Africa: A synthesis', Food Policy 48: 1-17.

Kansanga, M. (2017) 'Who you know and when you plough? Social capital and agricultural mechanization under the new green revolution in Ghana', International Journal of Agricultural Sustainability 15(6): 708-723. doi:10.1080 /14735903.2017.1399515.

Kansanga, M., Andersen, P., Kpienbaareh, D., Mason-Renton, S., Atuoye, K., Sano, Y., Antabe, R. and Luginaah, I. (2019) 'Traditional agriculture in transition: examining the impacts of agricultural modernization on smallholder farming in Ghana under the new Green Revolution', International Journal of Sustainable Development and World Ecology 26: 11-24.

Kansanga, M., Mkandawire, P., Kuuire, V. and Luginaah, I. (2019) 'Agricultural mechanization, environmental degradation and gendered livelihood implications in northern Ghana', Land Degradation \& Development 31(11):1422-1440.

Konings, P. (1981) Peasantry and state in Ghana: the example of the Vea irrigation project in the upper region of Ghana. ASC Working Paper Series. Leiden: African Studies Centre.

Konings, P. (1984) 'Capitalist rice farming and land allocation in Northern Ghana', The Journal of Legal Pluralism and Unofficial Law 16: 89-119.

Konings, P. (1986). The state and rural class formation in Ghana: a comparative analysis. London: Routledge.

Lay, J., Nolte, K. and Sipangule, K. (2018) Large-scale farms and smallholders: Evidence from Zambia. Working Paper 310. Hamburg: German Institute of Global and Area Studies (GIGA).

Liverpool-Tasie, L.S.O., Nuhu, A.S., Awokuse, T., Jayne, T., Muyanga, M., Aromolaran, A. and Adelaja, A. (2020) Spillover Effects of Medium-Scale Farms on Smallholder Behaviour and Welfare: Evidence from Nigeria. APRA Working Paper 38. Brighton: Future Agricultures Consortium. Available at: https://opendocs.ids.ac.uk/opendocs/ handle/20.500.12413/15712 (Accessed: 2 March 2021).

Lowder, S.K., Skoet, J. and Raney, T. (2016) 'The number, size, and distribution of farms, smallholder farms, and family farms worldwide', World Development 87: 16-29.

Masters, W.A., Djurfeldt, A.A., De Haan, C., Hazell, P., Jayne, T., Jirström, M. and Reardon, T. (2013) 'Urbanization and farm size in Asia and Africa: Implications for food security and agricultural research', Global Food Security 2: 156-165.

Miracle, M.P. and Seidman, A.W. (1968) State farms in Ghana. Madison: University of Madison Land Tenure Centre. 
Muyanga, M., Aromolaran, A., Jayne, T., Liverpool-Tasie, S., Awokuse, T. and Adelaja, A. (2019) Changing Farm Structure and Agricultural Commercialisation in Nigeria. APRA Working Paper 26. Brighton: Future Agricultures Consortium. Available at: https://opendocs.ids.ac.uk/opendocs/handle/20.500.12413/14576 (Accessed: 21 January 2021).

Netting, R.M. (1993) Smallholders, householders: Farm families and the ecology of intensive, sustainable agriculture. Stanford: Stanford University Press.

Ngeleza, G.K., Owusua, R., Jimah, K. and Kolavalli, S. (2011) Cropping practices and labor requirements in field operations for major crops in Ghana. What Needs to Be Mechanized? Washington DC: International Food Policy Research Institute, Development Strategy and Governance Division.

Owusu, M. (1975) 'Economic Nationalism, Pan-Africanism and the Military: Ghana's National Redemption Council', Africa Today 22(1): 31-50.

Shepherd, A.W. (1981) 'Capitalist Agriculture in Africa', Africa Development/Afrique et Développement 6(3): 5-21.

Shonhe, T. (2018). The political economy of agricultural commercialisation in Zimbabwe. APRA Working Paper 12. Brighton: Future Agricultures Consortium. Available at: https://opendocs.ids.ac.uk/opendocs/ handle/20.500.12413/13817 (Accessed: 21 January 2021).

Sutton, I. (1989) 'Colonial agricultural policy: The non-development of the Northern Territories of the Gold Coast', The International Journal of African Historical Studies 22: 637-669.

Totin, E., Segnon, A., Roncoli, C., Thompson-Hall, M., Sidibé, A. and Carr, E.R. (2021) 'Property rights and wrongs: Land reforms for sustainable food production in rural Mali', Land Use Policy 109: 105610.

Ugwu, D.S. (2006) 'Crop production in the compound farming system of southeastern Nigeria', Journal of Agriculture and Social Research 6(1): 1-10.

Van Der Westhuizen, D., Jayne, T.S. and Meyer, F.H. (2017) Causes and Consequences of Rising Tractor Use in Sub-Saharan Africa: Evidence from Tanzania. Poster prepared for presentation at the 2017 Agricultural \& Applied Economics Association Annual Meeting, Chicago, Illinois, July 30-August 1. Available at: https://ageconsearch.umn.edu/record/259944/files/Causes\%20and\%20consequences_Westhuizen.pdf (Accessed: 7 July 2021).

Veihe, A. (2000) 'Sustainable Farming Practices: Ghanaian Farmers' Perception of Erosion and Their Use of Conservation Measures', Environmental Management 25(4): 393-402. Available at:

https://www.ncbi.nlm.nih.gov/pubmed/10667945 (Accessed: 20 March 2019).

Wahab, I. (2020) A bird's eye-view of smallholder productivity: Current measurement shortfalls, farmer perceptions and rationality on rainfed family farms in Ghana. Doctoral Dissertation, Lund University.

Wahab, I., Jirström, M. and Hall, O. (2020) 'An integrated approach to unravelling smallholder yield levels: The case of small family farms, Eastern Region, Ghana', Agriculture 2020 10(206). doi:https://doi.org/10.3390/ agriculture10060206.

Yaro, J.A. (2010) 'Customary tenure systems under siege: contemporary access to land in Northern Ghana', GeoJournal 75(2): 199-214. doi:https://doi.org/10.1007/s10708-009-9301-x.

Yaro, J.A. (2012) 'Re-inventing traditional land tenure in the era of land commoditization: some consequences in periurban northern Ghana', Geografiska Annaler: Series B, Human Geography 94: 351-368.

Yaro, J. A. (2013) Rural development in northern Ghana. New York: Nova Science Pub Inc.

Yaro, J. A., Teye, J.K. and Torvikey, G.D. (2018) 'Historical context of agricultural commercialisation in Ghana: Changes in land and labour relations', Journal of Asian and African Studies 53: 49-63. 
Yaro, J.A., Wahab, I., Afful-Mensah, G. and Awenam, M.B. (2021) The Rise of Medium-Scale Farms in the Northern Savannah of Ghana: Farmland Invasion or an Inclusive Commercialised Agricultural Revolution? APRA Working Paper 70, Brighton: Future Agricultures Consortium

(c) APRA 2021

ISBN: 978-1-78118-860-6

DOI: 10.19088/APRA.2021.029

\section{(cc) BY-NC-ND}

This is an Open Access report distributed under the terms of the Attribution-Non Commercial-No Derivs 4.0 Unported (CC BY-NC-ND 4.0) Attribution - You must give appropriate credit, provide a link to the license, and indicate if changes were made. You may do so in any reasonable manner, but not in any way that suggests the licensor endorses you or your use. NonCommercial — You may not use the material for commercial purposes. NoDerivatives - If you remix, transform, or build upon the material, you may not distribute the modified material. You are free to: Share - copy and redistribute the material in any medium or format.

https://creativecommons.org/licenses/by-nc-nd/4.0/legalcode

If you use the work, we ask that you reference the APRA website (www.future-agricultures.org/apra/) and send a copy of the work or a link to its use online to the following address for our archive: APRA, Future Agricultures Consortium, University of Sussex, Brighton BN1 9RE, UK (apra@ids.ac.uk)

All APRA Working Papers go through a review process before publication.

\section{@creative}

\section{DO YOU HAVE COMMENTS ON THIS PAPER?}

We would welcome your feedback on this working paper!

To provide brief comments, please follow this link to our short APRA Working Paper Feedback form: https://goo.gl/forms/1iVnXhhrlGesfR9

Agricultural Policy Research in Africa (APRA) is a programme of the Future Agricultures Consortium (FAC) which is

generating new evidence and policy-relevant insights on more inclusive pathways to agricultural commercialisation in sub-Saharan Africa. APRA is funded with UK aid from the UK Foreign, Commonwealth \&

Development Office (FCDO) and will run from 2016-2022.

The APRA Directorate is based at the Institute of Development Studies (IDS), UK (www.ids.ac.uk), with regional hubs at the Centre for African Bio-Entrepreneurship (CABE), Kenya, the Institute for Poverty, Land and Agrarian Studies (PLAAS), South Africa, and the University of Ghana, Legon. It builds on more than a decade of research and policy engagement work by the Future Agricultures Consortium (www.future-agricultures.org) and involves more than 100 researchers and communications professionals in Africa, UK, Sweden and USA. 